\title{
Impact of Langmuir Turbulence on the Thermal Response of the Ocean Surface Mixed Layer to Supertyphoon Haitang (2005)
}

\author{
Xuefeng Zhang, ${ }^{\mathrm{a}}$ Peter C. Chu, ${ }^{\mathrm{b}}$ Wei Li, ${ }^{\mathrm{a}}$ Chang Liu,,${ }^{\mathrm{c}}$ LiAnXin Zhang, ${ }^{\mathrm{d}}$ CaiXia Shao, ${ }^{\mathrm{d}}$ \\ XiaOshuang Zhang, ${ }^{\mathrm{d}}$ GuOfang CHaO, ${ }^{\mathrm{d}, \mathrm{e}}$ AND YuXin ZhaO ${ }^{\mathrm{c}}$ \\ ${ }^{a}$ School of Marine Science and Technology, Tianjin University, Tianjin, China \\ ${ }^{\mathrm{b}}$ Naval Ocean Analysis and Prediction Laboratory, Department of Oceanography, Naval Postgraduate School, Monterey, California \\ ${ }^{\mathrm{c}}$ College of Automation, Harbin Engineering University, Harbin, China \\ ${ }^{\mathrm{d}}$ Key Laboratory of Marine Environmental Information Technology, National Marine Data and Information Service, \\ State Oceanic Administration, Tianjin, China \\ e Physical Oceanography Laboratory, Ocean University of China, Qingdao, China
}

(Manuscript received 1 July 2017, in final form 17 May 2018)

\begin{abstract}
Langmuir turbulence (LT) due to the Craik-Leibovich vortex force had a clear impact on the thermal response of the ocean mixed layer to Supertyphoon Haitang (2005) east of the Luzon Strait. This impact is investigated using a 3D wave-current coupled framework consisting of the Princeton Ocean Model with the generalized coordinate system (POMgcs) and the Simulating Waves Nearshore (SWAN) wave model. The Coriolis-Stokes forcing (CSF), the Craik-Leibovich vortex forcing (CLVF), and the second-moment closure model of LT developed by Harcourt are introduced into the circulation model. The coupled system is able to reproduce the upper-ocean temperature and surface mixed layer depth reasonably well during the forced stage of the supertyphoon. The typhoon-induced "cold suction" and "heat pump" processes are significantly affected by LT. Local LT mixing strengthened the sea surface cooling by more than $0.5^{\circ} \mathrm{C}$ in most typhoonaffected regions. Besides LT, Lagrangian advection of temperature also modulates the SST cooling, inducing a negative (positive) SST difference in the vicinity of the typhoon center (outside of the cooling region). In addition, CLVF has the same order of magnitude as the horizontal advection in the typhooninduced strong-vorticity region. While the geostrophy is broken down during the forced stage of Haitang, CLVF can help establish and maintain typhoon-induced quasigeostrophy during and after the typhoon. Finally, the effect of LT on the countergradient turbulent flux under the supertyphoon is discussed.
\end{abstract}

\section{Introduction}

Surface gravity waves can greatly affect turbulent mixing and dissipation in surface mixed layer mainly via breaking and nonbreaking ocean surface waves. Observations (Thorpe 1984; Terray et al. 1996) indicated that surface wave breaking enhances the rate of turbulent kinetic energy (TKE) dissipation near the ocean surface. In addition, the upper-ocean turbulence due to the Craik-Leibovich vortex forcing, namely, Langmuir turbulence (LT), significantly enhances upper-level turbulence mixing (Kantha and Clayson 2004, hereinafter KC04). The mean circulation and turbulence characteristics in the upper-ocean mixed layer can be modified by the enhanced turbulence. Besides LT, other nonbreaking

\footnotetext{
Corresponding author: Xuefeng Zhang, zhangxf@mail.nmdis. gov.cn
}

wave processes proposed by Babanin and Haus (2009) and Stoney et al. (2017), such as the wave orbital motion, can also modulate the upper-ocean mixed layer.

The effect of LT on upper-ocean thermal structure can be numerically investigated mainly through two ways: large-eddy simulation (LES) and Reynolds averaging method. LES using the equations by Craik and Leibovich (1976) can resolve the dominant scale of LT. LT exists through the Craik-Leibovich vortex forcing (CLVF), which comes from the interaction between surface waves' Stokes drift and mean current's vorticity. LES can be used to explore the effect of LT on the TKE budget and its contribution to the upper-ocean mixing (e.g., Skyllingstad and Denbo 1995; McWilliams et al. 1997; Li et al. 2013; Kukulka et al. 2012; Pearson et al. 2015). LES that only consists of the wind-wave equilibrium condition (McWilliams et al. 1997; Li et al. 2005; Polton and Belcher 2007) is, however, inappropriate for 
LT simulation under high-wind conditions during typhoon passage (Sullivan et al. 2012). Typhoons, especially supertyphoons, can generate large ocean surface frictional velocity and surface gravity waves, which then greatly increase the magnitude of wind-driven mean current shear and Stokes drift; this obviously affects mean ocean currents as well as vertical turbulent mixing in the upper-ocean mixed layer. In addition, winds and waves change with time rapidly, and the wind-wave equilibrium is hardly reached under typhoon passage, which results in a significant misalignment between wind and wave fields. Van Roekel et al. (2012) assessed the effects of misaligned Stoke drift and wind direction on Langmuir cells in the upper-ocean mixed layer. Rabe et al. (2015) investigated the upper-ocean turbulence combining a wave model with an LES model under extreme wind and complex wave fields. They indicated that LT plays a significant role in upper-ocean mixing under tropical cyclone conditions. The vertical velocity variance (VVV) underestimated the observed VVV without the LT effect in the model. In addition, the authors demonstrated that the misaligned wind and wave fields can suppress LT to levels closer to shear turbulence (ST).

Although LES can directly resolve the dominant scale of LT so only the subgrid turbulent scales are parameterized, it is computationally too intensive for a basin-scale simulation with a fine resolution $[O(1) \mathrm{m}]$. Instead, the turbulence closure scheme based on the Reynolds averaging method is a more appropriate way to be incorporated into a state-of-the-art 3D primitive equation ocean circulation model for investigating 3D response of the upper ocean to LT with a coarse resolution $\left[O\left(10^{3}-10^{4}\right) \mathrm{m}\right]$, even if all turbulent scales including LT cannot be directly resolved and need to be parameterized.

The Mellor-Yamada (MY) closure scheme (Mellor and Yamada 1982) is one of the most popular turbulent closure models based on the Reynolds averaging method. To model the LT mixing associated with CLVF, KC04 and Kantha et al. (2009) parameterized the rate of change of TKE through introducing the Stokes production (SP) into a MY-type closure model. They applied a one-dimensional (1D) mixed layer model to study the effect of TKE input from the SP on vertical mixing in the ocean. Their results indicated that the SP elevates the turbulent mixing throughout the mixed layer and improves the sea surface temperature (SST) prediction at the seasonal time scale. Following KC04, Zhang et al. (2012) included the SP in the MY-2.5 turbulent closure submodel used in the 3D Princeton Ocean Model with generalized sigma-coordinate system (POMgcs; Ezer and Mellor 2004) to investigate the summer surface mixed layer thermal structure in the
Yellow Sea. They found that the surface mixed layer can be well reproduced if the SP is included in the turbulent closure submodel. Recently, Harcourt (2013, 2015, hereinafter H15) developed a second-moment turbulent closure model of LT with the CLVF to capture important Langmuir turbulent mixing processes. Compared to $\mathrm{KC} 04, \mathrm{H} 15$ modified the stability function in the two-equation second moment closure model to match the CLVF term. In addition, H15 introduced inhomogeneous pressure-strain rate and pressurescalar gradient closures to repair some defects in the Reynolds stress model used in Harcourt (2013). The vertical momentum flux down the gradient of the Stokes drift was introduced, in addition to the conventional momentum flux down the gradient of the Eulerian velocity.

Unlike the MY-type turbulence models that are based entirely on Reynolds averaging equations, the K-profile parameterization (KPP) (Large et al. 1994) is a relatively simple bulk turbulence model, in which some empirically tuning constants are used for best modeling performance in different situations. The original KPP turbulent closure model has been modified to include the LT (McWilliams et al. 2014; Sinha et al. 2015). Recently, Reichl et al. (2016a) developed a sea-statedependent LT parameterization based on the original KPP under tropical cyclone (TC) conditions. The LT parameterization can adequately reproduce $1 \mathrm{D}$ responses of mean current and temperature to the TC simulated by the LES model. Then, Reichl et al. (2016b) investigated the impacts of sea-state-dependent LT on the ocean's 3D responses to an idealized TC based on the KPP-LT parameterization. While the original scheme significantly underestimated SST cooling caused by TC, the sea-statedependent LT parameterization improved the accuracy in predicting ocean response to the TC.

Besides LT, other Stokes drift-related mechanisms, such as Coriolis-Stokes forcing (CSF) and the resolvedscale CLVF, can also play important roles in dynamic and thermodynamic processes in the upper ocean. The CSF represents the interaction between the Stokes drift and the planetary vorticity, which can change the classical Ekman balance in the wind-driven surface boundary layer (Huang 1979; Chu 2015). McWilliams and Restrepo (1999) demonstrated that wave-driven current is comparable to wind-driven current in the basin-scale circulation. McWilliams et al. (2012) suggested that CSF and CLVF have main influences in the Ekman layer under conditions close to wind-wave equilibrium. McWilliams and Fox-Kemper (2013) further showed that surface fronts and filaments can adjust conservatively to accommodate the Stokes drift vortex force and Coriolis force from gravity waves in a new, balanced state instead of the 
inviscid state in a geostrophic, hydrostatic balance in the absence of surface gravity waves.

In this study, we use a 3D wave-current coupled model to investigate to what degree the sea-state-dependent LT can affect 3D ocean thermal structure under wind-wave inequilibrium condition in a realistic typhoon scenario. In addition, several other Stokes drift-related mechanisms are also investigated. First, as in Reichl et al. (2016b), CSF is introduced into the circulation model. Second, the resolved-scale CLVF is included in the horizontal momentum equations of the circulation model to modify the mean current dynamics. In addition, the Lagrangian advection term is employed in the potential temperature equation to investigate its contribution to SST cooling together with LT.

Many North Pacific typhoons pass through the region east of the Luzon Strait. As a representative case, Supertyphoon Haitang (2005) is chosen to investigate the effect of LT-induced mixing on the upper thermal structure east of the Luzon Strait using a wave-current coupled model. The paper is organized as follows. Model configuration and experiment design are given in section 2. LT parameterization is described in section 3 . Effects of wave and Stokes drift are presented in section 4. Thermal response due to the Stokes drift is depicted in section 5. Diagnostic analysis is given in section 6 , followed by conclusions in section 7 .

\section{Models and forcing fields}

\section{a. Circulation model}

POMges (Ezer and Mellor 2004) is a version of the Princeton Ocean Model, which is a 3D, primitive-equation, free-surface, coastal circulation model. It can be used to simulate coastal ocean circulations on diurnal, seasonal, and climate time scales. The MY-2.5 turbulent closure submodel is included in POMgcs to parameterize the vertical turbulent mixing in the surface and bottom boundary layers. It is well known that the MY-2.5 submodel underestimates the turbulent mixing in stably stratified flows because of the oversimplification of the parameterizations of pressure-velocity and pressure-temperature correlation terms. To overcome these deficiencies, more robust MYtype turbulent models, such as Kantha (2003) and Cheng et al. (2002), have been developed to replace the original MY-2.5 model. In addition, a more general distribution of vertical levels based on a generalized sigma-coordinate system (Ezer and Mellor 2004) is used to replace the standard sigma-coordinate system, which has the advantages of both sigma- and $z$-coordinate systems.

When CSF and the resolved-scale CLVF are involved in POMgcs, the horizontal momentum equations for the wave-phase-averaged Eulerian velocity $\mathbf{U}=(U, V)$ within the coordinate framework (Ezer and Mellor 2004) can be modified as follows:

$$
\begin{aligned}
& \Im^{S}(U)-f V s_{k}+g s_{k} \frac{\partial \eta}{\partial x}+\frac{g s_{k}}{\rho_{0}} \int_{k}^{0}\left[s_{k} \frac{\partial \rho^{\prime}}{\partial x}-\left(s_{x}+\eta_{x}\right) \frac{\partial \rho^{\prime}}{\partial k^{\prime}}\right] d k^{\prime}-\left(\frac{\partial s_{k} \tau_{x x}}{\partial x}+\frac{\partial s_{k} \tau_{x y}}{\partial y}\right)=\mathrm{CSF}_{x}+\mathrm{CLVF}_{x}+\frac{\partial}{\partial k}\left(\frac{K_{M}}{s_{k}} \frac{\partial U}{\partial k}\right), \\
& \Im^{S}(V)+f U s_{k}+g s_{k} \frac{\partial \eta}{\partial y}+\frac{g s_{k}}{\rho_{0}} \int_{k}^{0}\left[s_{k} \frac{\partial \rho^{\prime}}{\partial y}-\left(s_{y}+\eta_{y}\right) \frac{\partial \rho^{\prime}}{\partial k^{\prime}}\right] d k^{\prime}-\left(\frac{\partial s_{k} \tau_{x y}}{\partial x}+\frac{\partial s_{k} \tau_{y y}}{\partial y}\right)=\mathrm{CSF}_{y}+\mathrm{CLVF}_{y}+\frac{\partial}{\partial k}\left(\frac{K_{M}}{s_{k}} \frac{\partial V}{\partial k}\right),
\end{aligned}
$$

$$
\begin{aligned}
s_{x}= & \frac{\partial s}{\partial x}, \quad s_{y}=\frac{\partial s}{\partial y}, \quad s=z-\eta, \\
\mathrm{CSF}_{x}= & f V_{s} s_{k}, \quad \mathrm{CSF}_{y}=-f U_{s} s_{k}, \\
\mathrm{CLVF}_{x}= & V_{s}\left[s_{k} \frac{\partial V}{\partial x}-s_{k} \frac{\partial U}{\partial y}-\left(s_{x}+\eta_{x}\right) \frac{\partial V}{\partial k}\right. \\
& \left.+\left(s_{y}+\eta_{y}\right) \frac{\partial U}{\partial k}\right], \quad \text { and } \\
\mathrm{CLVF}_{y}= & -U_{s}\left[s_{k} \frac{\partial V}{\partial x}-s_{k} \frac{\partial U}{\partial y}-\left(s_{x}+\eta_{x}\right) \frac{\partial V}{\partial k}\right. \\
& \left.+\left(s_{y}+\eta_{y}\right) \frac{\partial U}{\partial k}\right],
\end{aligned}
$$

where $(x, y)$ are the horizontal coordinates; $k$ is the vertical coordinate (levels) with $s_{k}$ being the $k$ th-level thickness; $\Im^{S}(\cdot)=\partial(\cdot) / \partial t+\partial\left[(\cdot) U s_{k}\right] / \partial x+\partial\left[(\cdot) V s_{k}\right] / \partial y+$ $\partial[(\cdot) \omega] / \partial k$ is the total material derivative based on an $s$-coordinate transformation; $\omega$ is the corresponding vertical velocity; $(U, V)$ and $\left(U_{s}, V_{s}\right)$ are the east-west and north-south components of the Eulerian mean current and Stokes drift, respectively; $f$ is the Coriolis parameter; $\eta$ is the surface elevation; $\rho_{0}$ and $\rho^{\prime}$ are the reference density and density anomaly, respectively; $K_{M}$ is the vertical eddy viscosity coefficient; $\tau_{x x}, \tau_{y y}$, and $\tau_{x y}$ are the second-order normal and tangential stress tensors related to the horizontal viscosity; and $J^{S}$ is the 
differential operator of the total derivative in the s coordinate. The CSF and CLVF effects are represented by the two vectors below:

$$
\mathbf{C S F}=\left(\mathrm{CSF}_{x}, \mathrm{CSF}_{y}\right), \quad \mathbf{C L V F}=\left(\mathrm{CLVF}_{x}, \mathrm{CLVF}_{y}\right) .
$$

From Suzuki and Fox-Kemper (2016), one can see the wave-averaged Boussinesq equation has several different forms [see their Eqs. (1)-(5)]. The form including both CLVF and nonhydrostatic pressure terms [see their Eq. (2)] is mathematically equivalent to the one including the Stokes shear and Lagrangian advection [see their Eq. (5)]. The neglect of the nonhydrostatic pressure term indicates that the Stokes advection term of the momentum is not included in this study. In contrast, Blair et al. (2017) kept the Stokes advection term in the momentum equations, while the authors neglected the resolved-scale CLVF term. In addition, neither Blair et al. (2017) nor this study considers the vertical Stokes shear force. A complete inclusion of the nonhydrostatic pressure term will be explored in future studies.

Potential temperature $T$ and salinity $S$ equations are written as follows:

$$
\begin{aligned}
& \mathfrak{J}^{L}(T)=\frac{\partial}{\partial k}\left(\frac{K_{H}}{s_{k}} \frac{\partial T}{\partial k}\right)+\left(\frac{\partial s_{k} q_{T}}{\partial x}+\frac{\partial s_{k} q_{T}}{\partial y}\right)-\frac{\partial R}{\partial k}, \\
& \mathfrak{J}^{L}(S)=\frac{\partial}{\partial k}\left(\frac{K_{H}}{s_{k}} \frac{\partial S}{\partial k}\right)+\left(\frac{\partial s_{k} q_{S}}{\partial x}+\frac{\partial s_{k} q_{S}}{\partial y}\right),
\end{aligned}
$$

where $K_{H}$ is vertical mixing coefficient for tracers; $q_{T}$ and $q_{S}$ are terms pertinent to horizontal diffusion of $T$ and $S$, respectively; $R$ is heat radiation flux; and

$$
\mathfrak{J}^{L}=\frac{\partial(\cdot)}{\partial t}+\frac{\partial\left[(\cdot) U_{L} s_{k}\right]}{\partial x}+\frac{\partial\left[(\cdot) V_{L} s_{k}\right]}{\partial y}+\frac{\partial[(\cdot) \omega]}{\partial k}
$$

is the total material derivative including the Lagrangian advection of the tracers, where $U_{L}=U+U_{s}$ and $V_{L}=V+V_{s}$.

The model domain $\left(18^{\circ}-29^{\circ} \mathrm{N}, 116^{\circ}-127.5^{\circ} \mathrm{E}\right.$; Fig. 1) covers the adjacent seas of Taiwan, including the Luzon Strait. The NOAA 1-arc-min Gridded Global Relief Data (ETOPO1) is used for the bottom topography, and the $5-\mathrm{m}$ isobath is used to define the minimum water depth. The horizontal resolution is $1 / 20^{\circ}$ by $1 / 20^{\circ}$, which is high enough to resolve the main dynamic and thermodynamic processes under typhoon on synoptic and diurnal time scales. With this horizontal resolution, the mesoscale eddy-induced quasigeostrophic and typhooninduced upwelling/downwelling processes can be well resolved. These processes further contribute to turbulence mixing. The internal- and external-mode time steps are 180 and $3 \mathrm{~s}$, respectively. There are 35 vertical coordinate levels included in the configuration. Among the vertical levels, the sigma levels are used near a sloping bottom to follow the topography; the $z$ levels are used above the sigma levels with the upmost five levels at $0.0,2.5,5.0,10.0$, and $15.0 \mathrm{~m}$, enough to resolve the Stokes drift profile with an $e$-folding depth on the order of $O(10) \mathrm{m}$ under a supertyphoon.

The model initial fields include sea surface height, 3D velocity, temperature, and salinity in July 2005 , derived from the monthly mean fields of the China Ocean Reanalysis (CORA), which is a reanalysis dataset for China's coastal waters and adjacent seas (Han et al. 2011). The initial fields are constructed via a simple 3D linear interpolation algorithm. The lateral boundary conditions for sea surface height, 3D velocity, temperature, and salinity are also obtained from the CORA. Eight main tidal components of $\mathrm{M}_{2}, \mathrm{~S}_{2}, \mathrm{~K}_{1}, \mathrm{O}_{1}, \mathrm{~N}_{2}, \mathrm{~K}_{2}$, $\mathrm{P}_{1}$, and $\mathrm{Q}_{1}$ are imposed on the model lateral boundary via the Flather boundary condition (Flather 1976). The harmonic constants of tidal elevations and 2D tidal currents are obtained from the Oregon State University TOPEX/Poseidon Global Inverse Solution tidal model, version 7 (TPXO7), with $1 / 4^{\circ}$ resolution. The model is forced by both surface heat fluxes and wind stress. The surface heat fluxes include shortwave radiation, net longwave radiation, sensible heat, and latent heat fluxes, which are obtained from the National Centers for Environmental Prediction (NCEP) with the temporal resolution of $6 \mathrm{~h}$. Salt flux is not used in this study, indicating the evaporation and precipitation process are not considered. Wind stress will be discussed in section $2 \mathrm{c}$.

\section{b. Wave model}

The Simulating Waves Nearshore model (SWAN) is used to obtain wave parameters through solving the spectral action balance equation with sources and sinks (Booij et al. 1999). A detailed description of this model can be found in its user manual (http://www.swan. tudelft.nl). The domain, bottom topography, and horizontal resolution are the same as those in the circulation model mentioned in section 2a. The wave spectrum was discretized by 32 logarithmically spaced frequencies (with the minimum frequency of $0.03 \mathrm{~Hz}$ ) and 36 evenly spaced directions. The typhoon-enhanced crosscalibrated, multiplatform (CCMP) winds that are interpolated onto the ocean grid are also used to force the wave model. The time step is $180 \mathrm{~s}$, consistent with the internal-mode time step used in the circulation model.

\section{c. Typhoon wind field}

The 10-m wind field for Typhoon Haitang (2005) is constructed to drive both the circulation model and the 

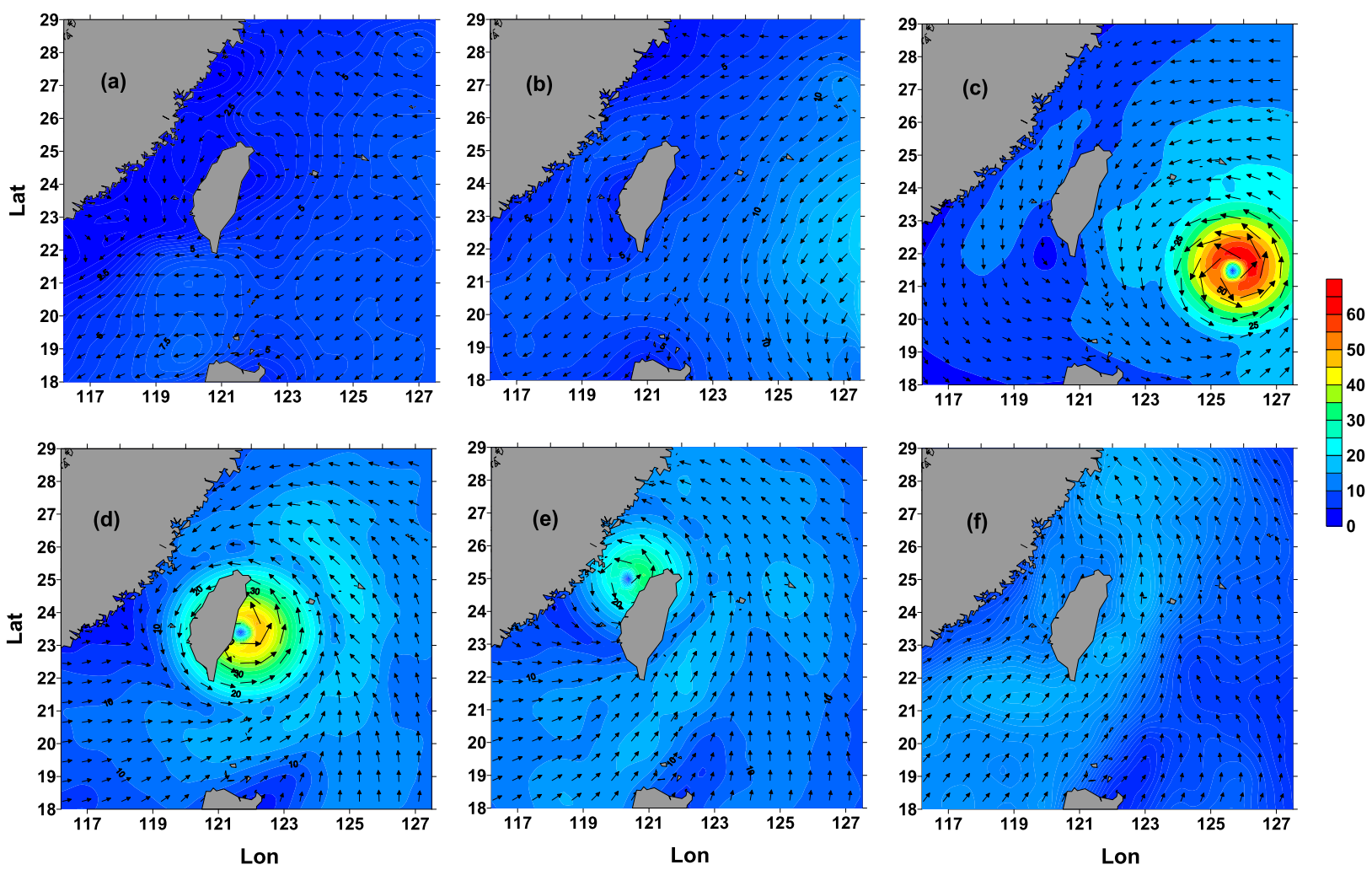

FIG. 1. Horizontal distribution of 10-m wind vectors and speeds (shading; $\mathrm{m} \mathrm{s}^{-1}$ ) at 0000 UTC on (a) 15, (b) 16, (c) 17, (d) 18, (e) 19, and (f) $20 \mathrm{Jul} 2005$.

wave model. High-resolution 6-h surface wind stress data of Typhoon Haitang (2005) are from the Joint Typhoon Warning Center, including the features of the TC, such as estimation of position, maximum sustained surface wind speed, and maximum and zero wind speed radii via a TC wind profile model (Carr and Elsberry 1997). This model was used to produce high-resolution surface wind for Tropical Cyclone Ernie (1996) (Chu et al. 2000) and Typhoon Muifa (2004) (Chu and Cheng 2008) to investigate the thermal and wave responses of the South China Sea. Next, the constructed 10-m wind field for Typhoon Haitang (2005) was assimilated into the CCMP ocean surface wind product with the spatial resolution of $1 / 4^{\circ}$ by $1 / 4^{\circ}$ and the temporal resolution of $6 \mathrm{~h}$, to update the gridded background wind field via a $3 \mathrm{D}$ variational data assimilation algorithm ( $\mathrm{Li}$ et al. 2008).

Figure 1 shows the horizontal distribution of reconstructed $10-\mathrm{m}$ wind vector and speed at 0000 UTC from 15 to 20 July 2005 using the wind profile model. Typhoon Haitang had not yet entered the study region on 15 July 2005 (Fig. 1a), when the wind speed remained low or moderate in the whole area. Then, the leading edge of Typhoon Haitang swept over the east of the study region on 16 July, where the wind speed began to increase (see Fig. 1b). Haitang intensified to the level of a supertyphoon when it reached the east of the Luzon Strait on 17 July (Fig. 1c), where the maximum wind speed was more than $65 \mathrm{~m} \mathrm{~s}^{-1}$. The right-reinforced structure occurred with a clear eye. Haitang continued to move toward northwest to the east of Taiwan with reduced wind speeds on 18 July (Fig. 1d) and then crossed over Taiwan Island with further weakening on 19 July (Fig. 1e). Finally, it made a landfall in southeast China on 19 July. At that time, the trailing edge of Haitang could still be identified from Fig. 1f.

\section{d. Wave-current coupled model framework}

Both POMgcs and SWAN are coupled through the model-coupling toolkit (MCT) in two-way data exchange. Specifically, the output of real-time current and sea level from POMgcs are the input for the SWAN to calculate the Doppler shift via the wave dispersion relation. The output of wave parameters and spectrum from the SWAN are the input of POMgcs to obtain the SP of TKE, CSF, and CLVF. For this study, similar to Reichl et al. (2016b), we disable the effect of the ocean model on the wave model for simplifying complicated physics; thus, a one-way coupled system from SWAN to POMgcs is implemented 
at every internal-mode time step. In addition, the typhoon wind field mentioned above is used to drive the coupled model system.

\section{LT and wave-breaking parameterization schemes}

\section{a. LT mixing}

In recent years, MY-type second-moment closure turbulence models have been modified to explore effects of surface waves on the upper-ocean dynamic and thermodynamic structures under high-wind conditions. Li et al. (2014) explored impacts of nonbreaking wave-stirring-induced mixing on upper-ocean thermal structure and typhoon intensity using a regional coupled atmosphere-ocean model. A wave-stirring-induced mixing parameterization developed by the authors was employed in the MY closure model. Results indicated that the parameterization improved the simulations of both ocean thermal structure and typhoon intensity. Based on an ocean model that included the MY closure scheme, Stoney et al. (2017) introduced a novel parameterization of mixing from unbroken surface waves to simulate ocean responses to TCs. Temperature biases in the upper ocean were typically reduced when the parameterization was included. Zhang et al. (2017) investigated impacts of wave-breaking-induced sea spray on ocean thermal structure during a typhoon passage using the MY closure model. When the effect of sea spray was considered, the maximum of sea surface cooling simulated by the MY closure model was closer to the satellite observation. The parameterization of LT based on the $\mathrm{KC} 04$ has also been applied to study the effect of LT on ocean shelf dynamics under strong winds. Using the LT parameterization in $\mathrm{KC} 04$, X. F. Zhang et al. (2014) showed that LT easily suppressed strong stratification and significantly increased the depth of the surface mixed layer under high wind conditions.

Discussions above indicate that the modification of the turbulence mixing based on MY-type secondmoment closure turbulence models can unveil the responses of the wave-induced turbulent mixing to complex TC conditions. To model LT mixing, the advanced LT parameterization developed by H15 is used in this study. The TKE and turbulent length scale equations based on generalized sigma coordinates are written as follows:

$$
\begin{aligned}
& \Im^{S}\left(q^{2}\right)=\frac{\partial}{\partial k}\left(\frac{K_{q}}{s_{k}} \frac{\partial q^{2}}{\partial k}\right)+\frac{2 g}{\rho_{0}} K_{H} \frac{\partial \tilde{\rho}}{\partial k}-\frac{2 s_{k} q^{3}}{B_{1} l}+F_{q}+\frac{2}{s_{k}}\left[-\overline{u w}\left(\frac{\partial U}{\partial k}+\frac{\partial U_{s}}{\partial k}\right)-\overline{v w}\left(\frac{\partial V}{\partial k}+\frac{\partial V_{s}}{\partial k}\right)\right], \quad \text { and } \\
& \Im^{S}\left(q^{2} l\right)=\frac{\partial}{\partial k}\left(\frac{K_{q}}{s_{k}} \frac{\partial q^{2} l}{\partial k}\right)+\frac{q^{3}}{B_{1}} \tilde{W}+F_{l}+E_{1} l\left\{\frac{1}{s_{k}}\left[-\overline{u w}\left(\frac{\partial U}{\partial k}+\frac{E_{6}}{E_{1}} \frac{\partial U_{s}}{\partial k}\right)-\overline{u w}\left(\frac{\partial V}{\partial k}+\frac{E_{6}}{E_{1}} \frac{\partial V_{s}}{\partial k}\right)\right]+E_{3} \frac{g}{\rho_{0}} K_{H} \frac{\partial \tilde{\rho}}{\partial k}\right\},
\end{aligned}
$$

where $q^{2} / 2$ is TKE; $l$ is the turbulent length scale; $K_{H}$ and $K_{q}$ are the vertical eddy diffusion coefficients for the temperature and TKE, respectively; $\tilde{\rho}$ is the density corrected for adiabatic lapse rate; $F_{q}$ and $F_{l}$ are the horizontal diffusion terms for TKE and turbulent macroscale, respectively; $\tilde{W}$ is the wall proximity function; $B_{1}, E_{1}$, and $E_{3}$ are the model constants, as those used in Kantha (2003); $E_{6}$ is an LT-related model constant as in $\mathrm{KC} 04$; and $K_{M S}$ is a new vertical eddy viscosity for the component down the Stokes drift gradient $\partial \mathbf{U}_{s} / \partial k$. The $-\overline{u w}$ and $-\overline{v w}$ are components of the turbulent Reynolds stress per unit mass. In $\mathrm{KC} 04$,

$$
\begin{aligned}
& \overline{u w}=-K_{M}\left(\frac{\partial U}{\partial k}+\frac{\partial U_{s}}{\partial k}\right) \quad \text { and } \\
& \overline{v w}=-K_{M}\left(\frac{\partial V}{\partial k}+\frac{\partial V_{s}}{\partial k}\right) .
\end{aligned}
$$

In H15,

$$
\begin{aligned}
& \overline{u w}=-\left(K_{M} \frac{\partial U}{\partial k}+K_{M S} \frac{\partial U_{s}}{\partial k}\right) \quad \text { and } \\
& \overline{v w}=-\left(K_{M} \frac{\partial V}{\partial k}+K_{M S} \frac{\partial V_{s}}{\partial k}\right) .
\end{aligned}
$$

Note that if $K_{M S}$ in Eqs. (12a) and (12b) is replaced by $K_{M}$, $\mathrm{H} 15$ is degraded to the same expressions as in $\mathrm{KC0} 4$ [Eqs. (11a) and (11b)]. To better model LT, we set sigmacoordinate-based $K_{M S}$ according to $\mathrm{H} 15$ as follows:

$$
\begin{aligned}
& K_{M S}=q l S_{M S}, \quad \text { and } \\
& S_{M S}=\frac{A_{1}\left(1-f_{z}^{S}\right)\left(1-6 A_{1} / B_{1}\right)}{1-9 A_{1} A_{2} G_{H}-9 A_{1}^{2}\left(1-f_{z}^{S}\right) l^{2} q^{-2} s_{k}^{-2} \frac{\partial \mathbf{U}}{\partial k} \cdot \frac{\partial \mathbf{U}_{s}}{\partial k}},
\end{aligned}
$$

where $A_{1}$ and $A_{2}$ are the model constants, as in Kantha (2003); $G_{H}=-l^{2} q^{-2} N^{2} ; N$ is the buoyancy frequency; and $f_{z}^{s}$ is the surface-proximity function [see Eq. (34) in $\mathrm{H} 15]$. 

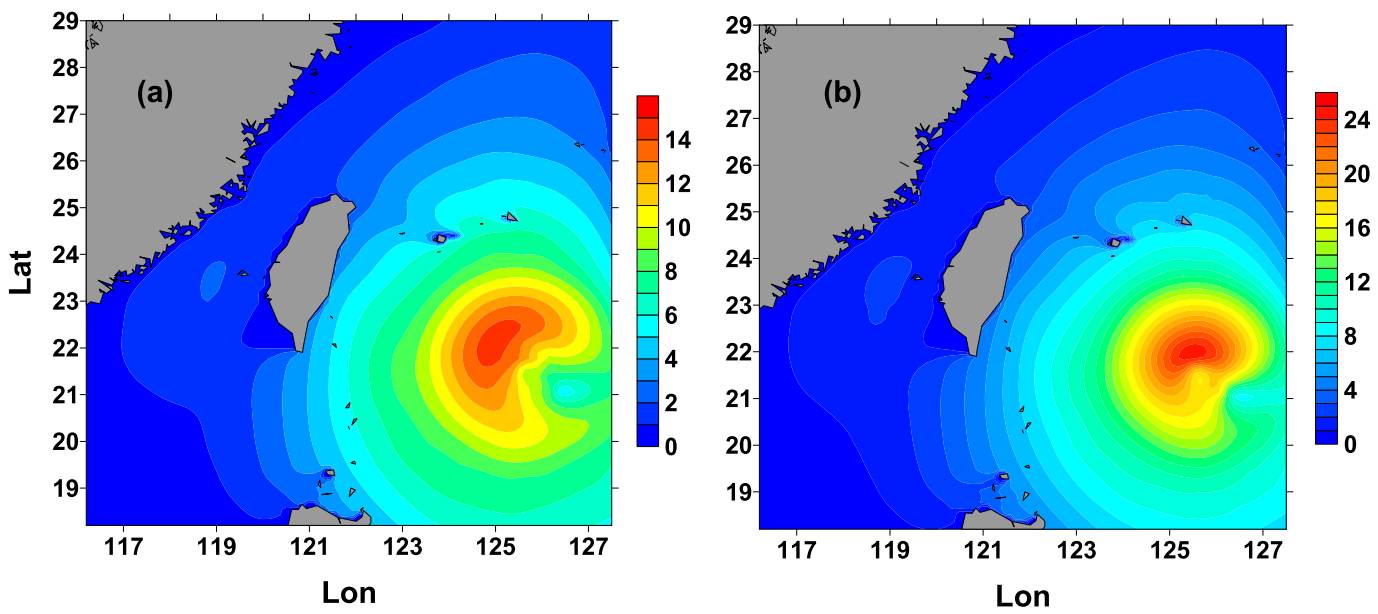

FIG. 2. Horizontal distribution of significant wave height $(\mathrm{m})$ with the drag coefficient parameterization from (a) Zijlema et al. (2012) or (b) Wu (1982) at 0000 UTC on 17 Jul 2005.

\section{b. Wave-breaking-enhanced mixing}

Wave-breaking-enhanced turbulence near the sea surface is considered in this study. The boundary condition for the TKE equation follows Craig and Banner (1994):

$$
K_{q} \frac{\partial q^{2}}{\partial z}=2 \alpha u_{\tau}^{3}, \quad z=0
$$

where $u_{\tau}$ is the waterside friction velocity and $\alpha$ is the "wave energy factor." The surface diffusion boundary condition provides the wave-breaking-enhanced turbulence near the surface layer. Zhang et al. (2011) identified the effect of breaking surface waves on upper-ocean mixed layer deepening in the Yellow Sea in summer. A better mixed layer was reconstructed when the traditional wall layer approximation condition is replaced by the Craig-Banner boundary condition. In addition, the turbulent macroscale $l$ is modified according to Mellor and Blumberg (2004):

$$
l=\max \left(\kappa z_{w}, l_{z}\right)
$$

where $l_{z}$ is the "conventional" empirical length scale calculated prognostically by the turbulence closure scheme; $\kappa$ is the von Kármán Constant $(0.4) ; z_{w}=$ $\beta\left(u_{\tau}^{2} / g\right)$ is the wave-related surface roughness length, which denotes the relevant scale of turbulence; and $\beta$ is the Charnock coefficient. Jones and Monismith (2008) and Carniel et al. (2009) suggested suitable choices of $\beta=32000$ and $\beta=56000$, respectively. In this study, $\beta$ is taken as $4 \times 10^{4}$ (Zhang et al. 2012). To improve the performance of the model in simulating the upper-ocean mixed layer, the wave-affected uncertain parameters, such as $\alpha$ and $\beta$, can be optimally estimated using available observations deployed in the upper ocean through the variational method (Zhang et al. 2015).

\section{Wave and Stokes drift}

\section{a. Sensitivity of significant wave height to the drag coefficient}

The sensitivity of significant wave height to the drag coefficient under a supertyphoon is examined first. SWAN has had extensive applications in hurricane wave simulation and forecast (Kennedy et al. 2011; Dietrich et al. 2011). Holthuijsen et al. (2012) investigated wave characteristics in extreme hurricanes using SWAN. There are two kinds of drag coefficient parameterizations in SWAN. The first kind is based on Wu (1982):

$$
C_{D}=\left(0.8+0.065 U_{10}\right) \times 10^{-3}
$$

where $U_{10}$ is the wind speed at $10 \mathrm{~m}$, and the relationship is valid for wind speeds of $0-50 \mathrm{~m} \mathrm{~s}^{-1}$. For wind speed higher than $50 \mathrm{~m} \mathrm{~s}^{-1}$, the drag coefficient of $50 \mathrm{~m} \mathrm{~s}^{-1}$ is used. The second kind is used by Zijlema et al. (2012) based on the polynomial fitting

$$
C_{D}=\left(0.55+2.97 \tilde{U}-1.49 \tilde{U}^{2}\right) \times 10^{-3}
$$

where $\tilde{U}=U_{10} / U_{\text {ref }}$, and $U_{\text {ref }}$ is the reference wind speed, set to $31.5 \mathrm{~m} \mathrm{~s}^{-1}$. The $C_{D}$ derived from Eq. (18) is lower than that from Eq. (17) by more than $30 \%$ for hurricane wind speed $\left(U_{10} \geq 32.6 \mathrm{~m} \mathrm{~s}^{-1}\right)$. Zijlema et al. (2012, p. 22) stated that "the polynomial fitting $C_{D}$ increases almost linearly with wind speed up to $\sim 20 \mathrm{~m} \mathrm{~s}^{-1}$, then levels off and decreases again at $\sim 35 \mathrm{~m} \mathrm{~s}^{-1}$ to rather a low value 
at $60 \mathrm{~m} \mathrm{~s}^{-1}$ wind speed." The bubbles and sea sprays in hurricane-ocean interaction may cause such a decrease of $C_{D}$ under high wind (Hsu et al. 2017). Powell et al. (2003) suggested that spray droplets can influence the airflow dynamics to form a very stable and limiting saturation boundary layer over the ocean at wind speed exceeding $33 \mathrm{~m} \mathrm{~s}^{-1}$, which is responsible to the decrease of $C_{D}$. Others suggested the drag coefficient levels off and even decreases at high wind speed (Emanuel 1995; Jarosz et al. 2007; Soloviev et al. 2014). More discussions can be found in Zhang et al. (2017).

Figure 2 presents the simulated horizontal distribution of significant wave height at 0000 UTC 17 July 2005 by the wave component (SWAN) within the wavecurrent coupled model framework using the two drag coefficient parameterizations. The maximum significant wave height using $C_{D}$ based on Zijlema et al. (2012) reached $\sim 15 \mathrm{~m}$, almost the same magnitude as that simulated by Fan et al. (2009) (see their Fig. 4a) under the extreme Tropical Cyclone Ivan (2004), which had almost identical maximum wind speed and similar horizontal pattern as well as moving speed with the Supertyphoon Haitang (2005). In contrast, the maximum significant wave height with $C_{D}$ from Wu (1982) is more than $25 \mathrm{~m}$ (Fig. 2b), which is a $40 \%$ overestimation compared with that based on Zijlema et al. (2012).

Figure 3a shows the time series of $10-\mathrm{m}$ wind speed at $\left(21.5^{\circ} \mathrm{N}, 125.5^{\circ} \mathrm{E}\right)$. A double-peak structure existed; namely, the wind speed gradually increased to more than $50 \mathrm{~m} \mathrm{~s}^{-1}$ from 0 to $40 \mathrm{~h}$ and then had a sharp decrease to less than $5 \mathrm{~m} \mathrm{~s}^{-1}$ when the typhoon eye passed through the site; subsequently, it had a rapid increase to more than $35 \mathrm{~m} \mathrm{~s}^{-1}$ at about $56 \mathrm{~h}$. The $C_{D}$ from $\mathrm{Wu}$ (1982) gives a consistent double-peak structure with $10-\mathrm{m}$ wind speed (red line in Fig. $3 \mathrm{~b}$ vs Fig. 3a); the structure is determined by the linear fitting relationship in Eq. (17). The $C_{D}$ based on Zijlema et al. (2012) has two minima between 30 and $60 \mathrm{~h}$ (see the blue curve in Fig. 3b). The first minimum was caused by the decrease of $C_{D}$ with the increase of wind speed under high wind $\left(>35 \mathrm{~m} \mathrm{~s}^{-1}\right)$, and the second minimum corresponded to the typhoon eye approaching. The overestimated $C_{D}$ based on Wu (1982) resulted in a severely overestimated significant wave height (black vs red curves in Fig. $3 \mathrm{c}$ ). Therefore, $C_{D}$ based on Zijlema et al. (2012) is employed in both ocean and wave models to translate the $10-\mathrm{m}$ wind speed to surface stress in this study.

\section{b. Stokes drift and e-folding depth}

Three methods are available to calculate the Stokes drift $\mathbf{U}_{s}$ and depth scale $D_{s}$. The first method is
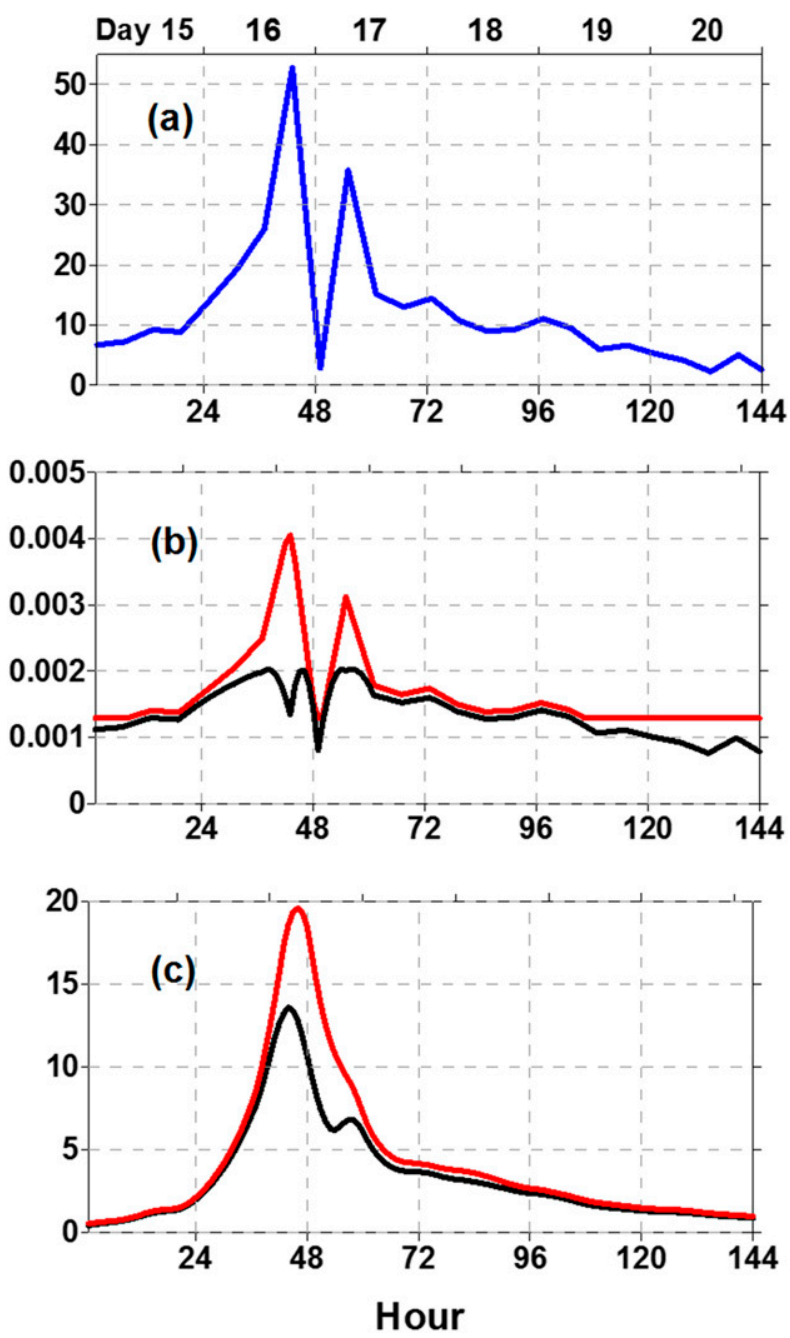

FIG. 3. Time series of (a) $10-\mathrm{m}$ wind speed $\left(\mathrm{m} \mathrm{s}^{-1}\right)$, (b) drag coefficient, and (c) significant wave height $(\mathrm{m})$ with the drag coefficient parameterization from Zijlema et al. (2012) (black) and $\mathrm{Wu}(1982)(\mathrm{red})$ at $\left(21.5^{\circ} \mathrm{N}, 125.5^{\circ} \mathrm{E}\right)$. The horizontal axis represents the hour relative to 0000 UTC 15 Jul 2005.

based on the spectrum itself following Reichl et al. (2016a):

$$
\mathbf{U}_{s}(z)=\int_{0}^{k_{L}} \int_{0}^{2 \pi} \psi(k, \theta) 2 \omega \exp (2 k z) \mathbf{k} d \theta d k
$$

where $\psi$ is the wavenumber direction spectrum, $\theta$ is the wave direction, $\omega$ is the angular frequency, $\mathbf{k}$ is the wavenumber vector, and $k_{L}$ is the upper bound of the wavenumber integration corresponding to the wavelength of $1 \mathrm{~m}$. The Stokes $e$-folding depth $D_{s}$ is calculated according to the depth at which the Stokes drift decays to $e^{-1}\left|\mathbf{U}_{s}(0)\right|$.

The second method uses SWAN-output wave parameters, assuming a monochromatic wave (X. S. Zhang et al. 2014): 

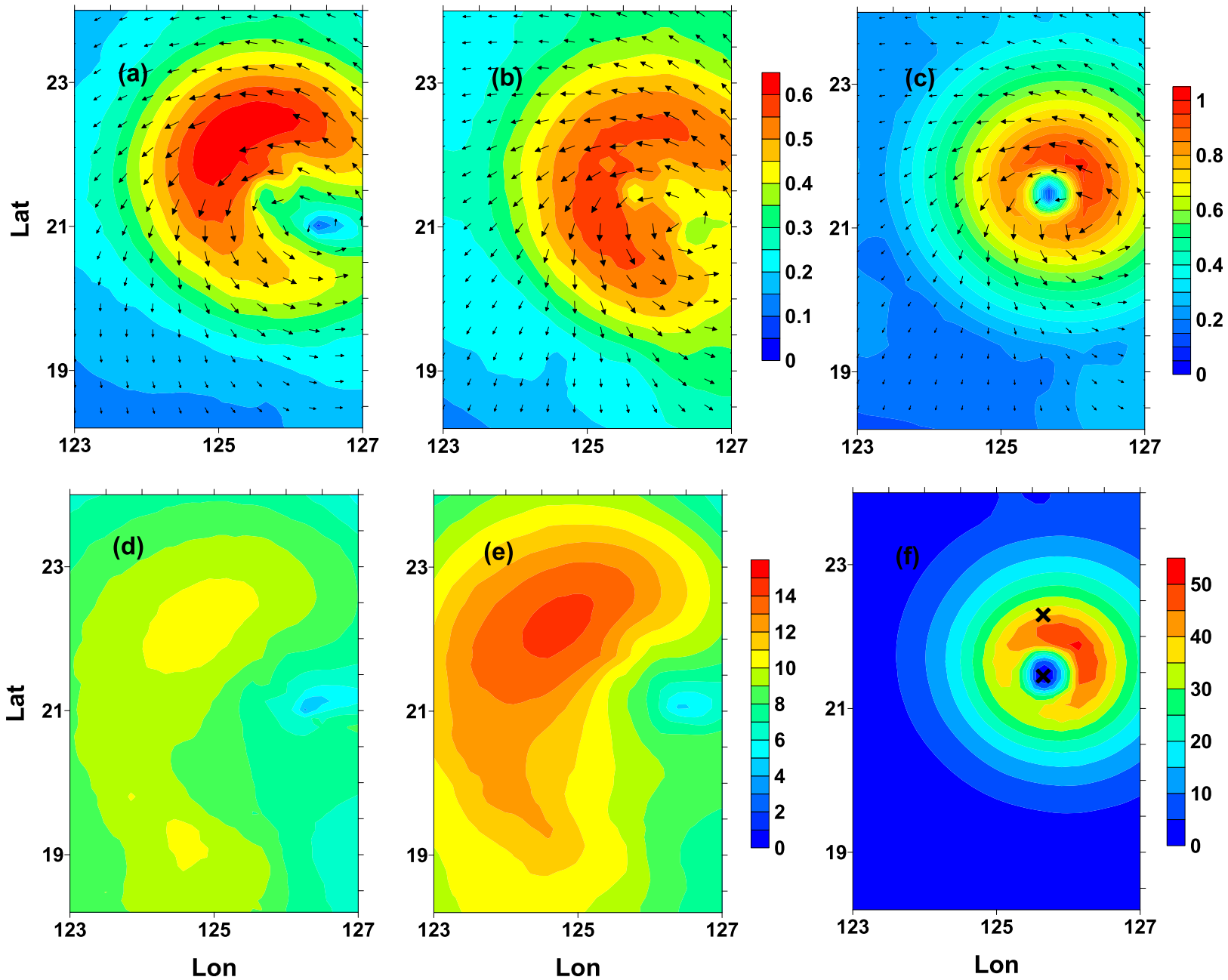

FIG. 4. (top) Stokes drift $U_{s}\left(\mathrm{~m} \mathrm{~s}^{-1}\right)$ and (bottom) the Stokes depth scale $D_{s}$ (m) from (a),(d) wave spectrum, (b),(e) bulk parameterization and (c),(f) wind-wave empirical relationship at 0000 UTC 17 Jul 2005.

$$
\begin{aligned}
\mathbf{U}_{s}(z) & =\left|\mathbf{U}_{s}(0)\right| \exp \left(\frac{z}{D_{s}}\right) \mathbf{k}, \quad\left|\mathbf{U}_{s}(0)\right|=\frac{2 \pi^{3} H_{s}^{2}}{g P^{3}}, \\
D_{s} & =\frac{g P^{2}}{8 \pi^{2}},
\end{aligned}
$$

where $g$ is the gravity and $H_{s}$ and $P$ are significant wave height and wave peak period, respectively.

The third method does not involve wave spectrum but uses the assumption of a fully developed wave. It uses some empirical correlations, such as in Li and Garrett (1993)
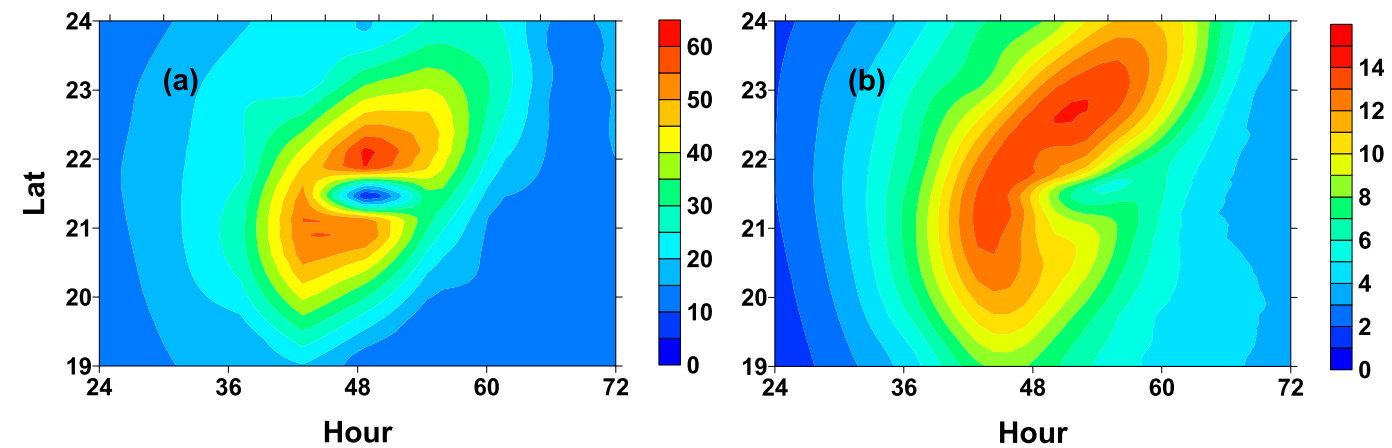

FIG. 5. Latitude-time Hovmöller diagram of (a) 10-m wind speed $\left(\mathrm{m} \mathrm{s}^{-1}\right)$ and (b) significant wave height (m) at $125.5^{\circ} \mathrm{E}$ at $0000 \mathrm{UTC} 17 \mathrm{Jul} 2005$. 

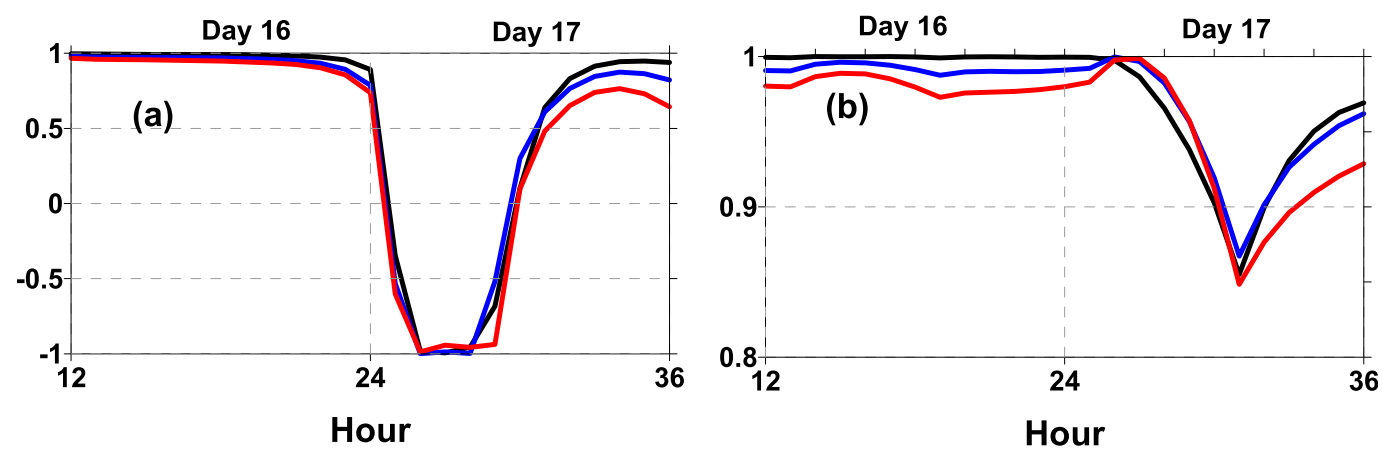

FIG. 6. Misalignment angle between wind and Stokes drift at (a) $\left(21.5^{\circ} \mathrm{N}, 125.5^{\circ} \mathrm{E}\right)$ and (b) $\left(22.5^{\circ} \mathrm{N}, 125.5^{\circ} \mathrm{E}\right)$ at the depth of 0 (black), 5 (blue), and $10 \mathrm{~m}$ (red) on the forced stage of Typhoon from 36 to $60 \mathrm{~h}$. The horizontal axis represents the hour relative to 0000 UTC 15 Jul 2005.

and in Harcourt and D'Asaro (2008), to estimate the Stokes drift:

$$
\begin{aligned}
\mathbf{U}_{s}(z) & =\left|\mathbf{U}_{s}(0)\right| \exp \left(\frac{z}{D_{s}}\right) \mathbf{k}, \\
\left|\mathbf{U}_{s}(0)\right| & =(0.014-0.015)\left|\mathbf{U}_{10}\right|, \\
D_{s} & =0.12 \frac{\left|\mathbf{U}_{10}\right|^{2}}{g} .
\end{aligned}
$$

Sullivan et al. (2012) suggested that the Stokes drift is better calculated from the wave spectrum [Eq. (19)] than from the bulk parameterization [Eq. (20)]. If the wave spectrum is not available, some empirical correlations such as Eq. (21) can be used to estimate the Stokes drift.

Since many ocean model applications are not always carried out under a wave-current coupled model framework, the empirical correlations [Eqs. (20) and (21)] are often used. We first discuss the three existing methods to compute the Stokes drift vector. The $\left|\mathbf{U}_{s}\right|$ derived from the wave spectrum (Fig. 4a) is larger (smaller) than the counterpart derived from the bulk parameterization (Fig. 4b) in the foreside region of the typhoon (rear quadrant region of typhoon inside the eye). The Stokes $e$-folding depth $D_{s}$ is about $30 \%$ smaller from the wave spectrum than from the bulk parameterization (Fig. 4d vs Fig. 4e). Tamura et al. (2012) indicated that $\left|\mathbf{U}_{s}\right|$ is underestimated and $D_{s}$ is overestimated using the bulk parameterization, which is what we see from our results. Sullivan et al. (2012) argued that the Stokes drift should be computed from the wave spectrum itself rather than from a monochromatic wave field or some wind-wave equilibrium relationship under complex wind and wave conditions. In addition, $\left|\mathbf{U}_{s}\right|$ is overestimated by $40 \%$ and $D_{s}$ is severely overestimated by about a factor of 5 using the wind-wave empirical relationship (Fig. 4c) compared with using the wave spectrum (Fig. 4f). Moreover, the horizontal distribution of both $\left|\mathbf{U}_{s}\right|$ and $D_{s}$ were almost the same as the typhoon pattern with maximum values located on the right of the typhoon moving track, which differed from the wave pattern shown in Fig. 4a (Fig. 4d), indicating the ad hoc empirical relationship can result in an arbitrary overestimation of LT mixing under typhoon con-

\begin{tabular}{|c|c|c|c|c|}
\hline Experiment name & $\begin{array}{c}\text { Inclusion of CSF, } \\
\text { CLVF, and Lagrangian } \\
\text { advection }\end{array}$ & $\begin{array}{l}\text { Inclusion } \\
\text { of LT }\end{array}$ & $\begin{array}{c}\text { Inclusion of } \\
\text { wave breaking }\end{array}$ & Description \\
\hline CTRL & No & No & Yes & $\begin{array}{l}\text { Integration of POMgcs from } 1 \text { to } 31 \mathrm{Jul} 2005 \text { without } \\
\text { considering the effect of Stoke drift. }\end{array}$ \\
\hline SPWAVE & Yes & Yes & Yes & $\begin{array}{l}\text { Integration of POMgcs-SWAN coupled model for } \\
\text { the same time as CTRL with the effect of LT. The CSF } \\
\text { and CLVF are included through the wave-current } \\
\text { interaction, and SP of TKE is included through the } \\
\text { wave-turbulent interaction. }\end{array}$ \\
\hline SPONLY & No & Yes & Yes & $\begin{array}{l}\text { As in SPWAVE, except the CSF, CLVF, and Lagrangian } \\
\text { advection are absent. }\end{array}$ \\
\hline SPWAVE_noLT & Yes & No & Yes & As in SPWAVE, except LT is absent. \\
\hline SPWAVE_nobreaking & Yes & Yes & No & As in SPWAVE, except wave breaking is absent. \\
\hline
\end{tabular}
dition. In this study, since the wave spectrum is available

TABLE 1. Experiment setups. 

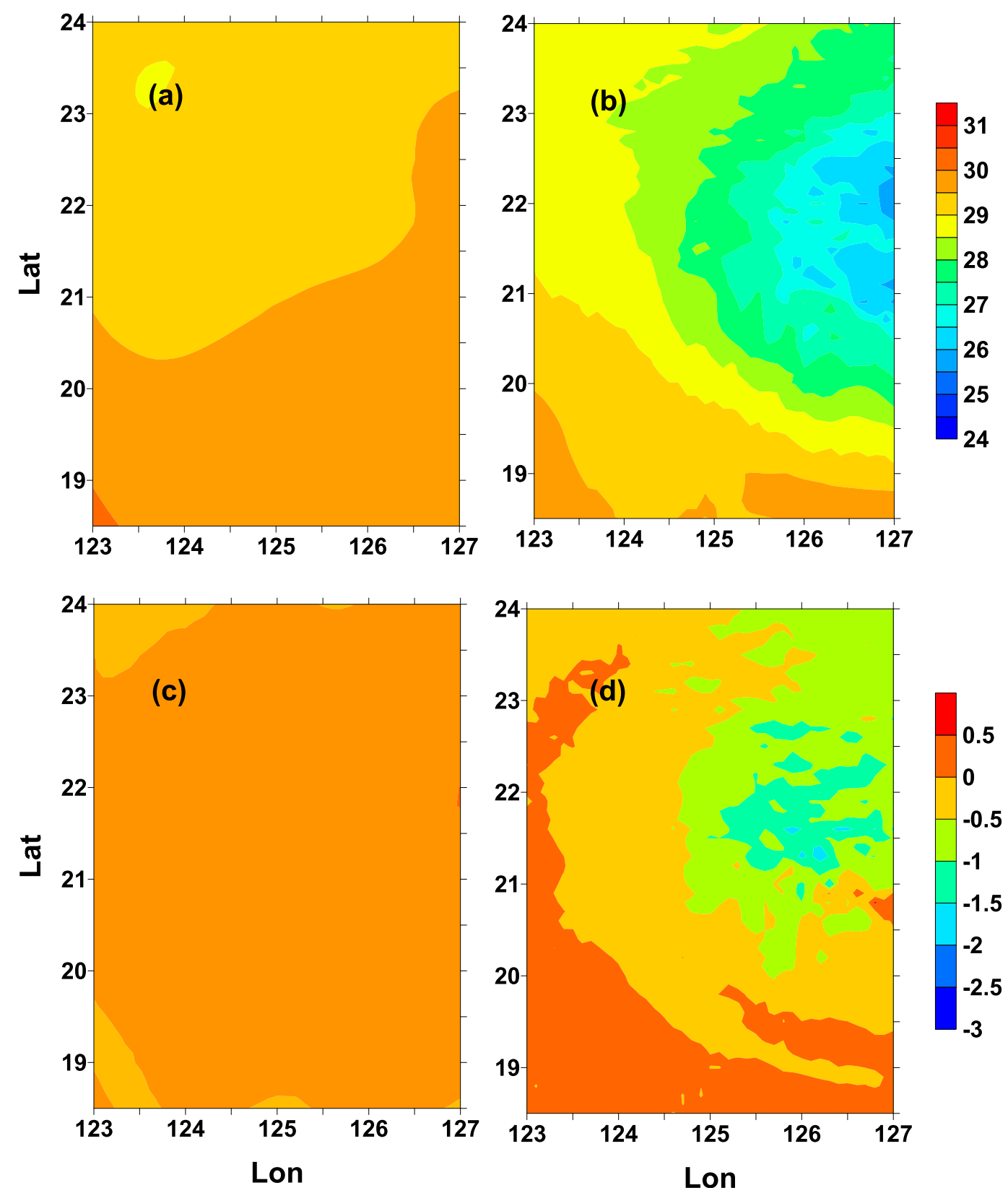

FIG. 7. Horizontal distribution of SST in the CTRL experiment $\left({ }^{\circ} \mathrm{C}\right)$ on (a) 15 (pretyphoon stage) and (b) $17 \mathrm{Jul}$ (typhoon-forced stage). SST difference between the SPWAVE and CTRL experiments (SPWAVE minus CTRL) on (c) 15 and (d) 17 Jul 2005.

through the wave-current coupled model, it is used to estimate the Stokes drift vector directly.

\section{c. Wind-wave misalignment characteristic under Typhoon Haitang}

Figures $5 \mathrm{a}$ and $5 \mathrm{~b}$ present the latitude-time Hovmöller diagrams of $10-\mathrm{m}$ wind speed and significant wave height at $125.5^{\circ} \mathrm{E}$, respectively. At 0000 UTC 17 July, both fields had tilted elliptical patterns because
Haitang translated from southeastward to northwestward direction. The wind-wave inequilibrium showed up around the typhoon eye region, indicating the misalignment between wind and wave fields there. The misalignment angle can be defined according to Rabe et al. (2015) by

$$
\cos [\theta(t, z)]=\frac{\mathbf{U}_{10}(t) \cdot \mathbf{U}_{s}(t, z)}{\left|\mathbf{U}_{10}(t)\right| \cdot\left|\mathbf{U}_{s}(t, z)\right|} .
$$



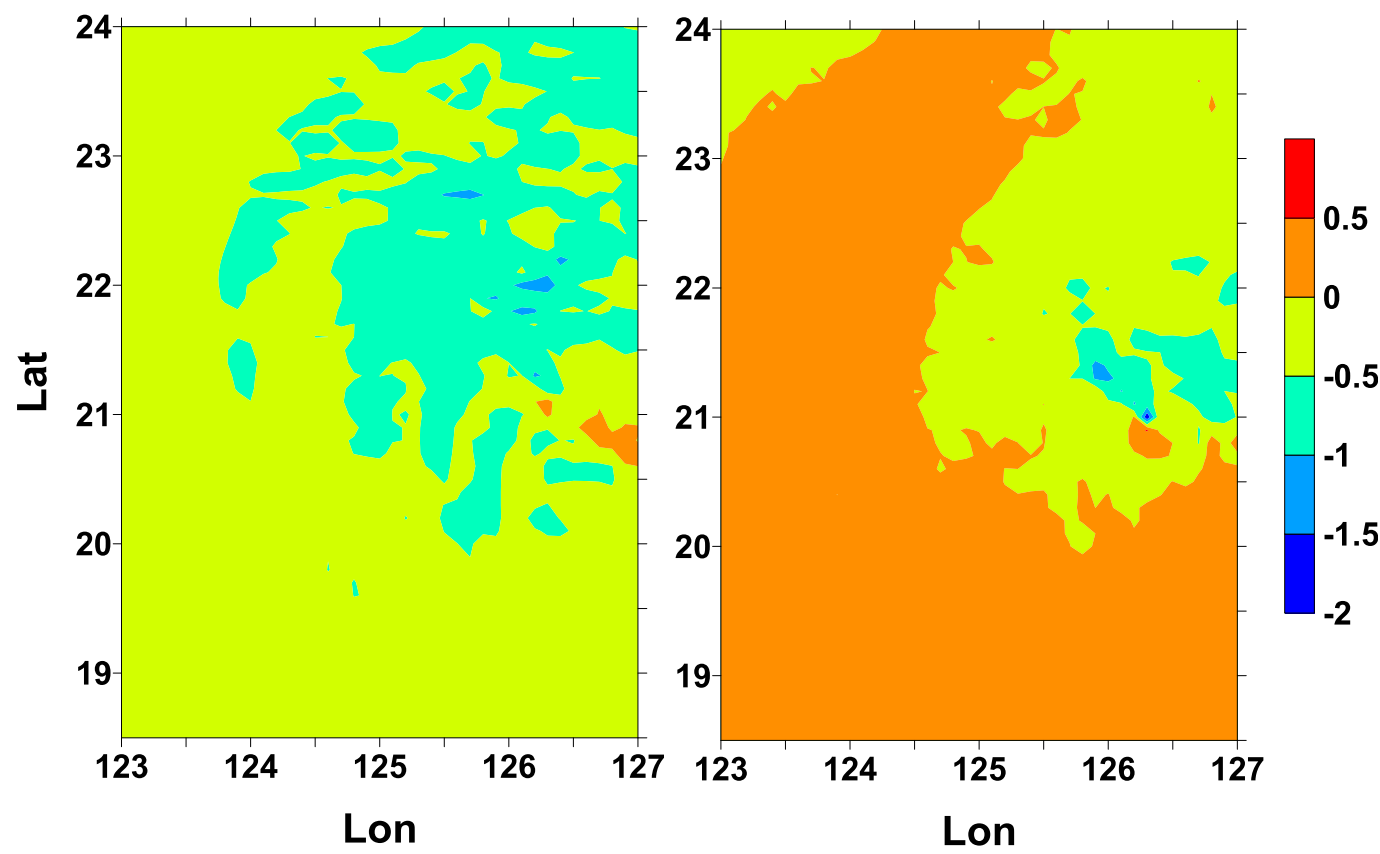

FIG. 8. SST difference on 17 Jul 2005 (a) between SPONLY and CTRL experiments and (b) between SPWAVE and SPONLY experiments.

Time series of the misalignment angle at $\left(21.5^{\circ} \mathrm{N}\right.$, $\left.125.5^{\circ} \mathrm{E}\right)$ and $\left(22.5^{\circ} \mathrm{N}, 125.5^{\circ} \mathrm{E}\right)$ and at depths 0,5 , and $10 \mathrm{~m}$ from 36 to $60 \mathrm{~h}$ are shown in black, blue, and red curves in Figs. 6a and 6b, respectively. The two locations were under the eye and near the maximum wind speed region, respectively (black crosses in Fig. 4f). The Stokes drift profiles began to become severely misaligned with the wind field in the eye region, the direction cosines of the misalignment angle varied from 1 to -1 (see Fig. 6a), consistent with Rabe et al. (2015). In contrast, the windwave alignment characteristic almost remained within the upper layer under the maximum wind (see Fig. 6b). The effect of the misalignment on LT mixing will be discussed in section 6 .

\section{Thermal response due to Stokes drift}

Two experiments are conducted first: the control run (CTRL) and one with LT mixing added (SPWAVE). Table 1 shows detailed experimental setups. The CTRL serves as a benchmark, and oceanic thermal response to LT is identified from comparing simulated results of CTRL and SPWAVE with the observations.

Figure 7 shows the horizontal distributions of SST in CTRL and the SST difference between SPWAVE and CTRL during the two periods of pretyphoon and typhoon-forced stages. The SST during the pretyphoon stage (15 July) exhibited a distribution that decreased from south to north (Fig. 7a). When Haitang had developed into a supertyphoon on 17 July, typhooninduced SST cooling was significant (Fig. 7b). The SST was reduced by more than $5^{\circ} \mathrm{C}$ compared with the pretyphoon stage. The SST difference between SPWAVE and CTRL during the pretyphoon stage was small (Fig. 7c) in the whole deep water region east of the Luzon Strait, indicating the effect of LT and other wave terms on SST were weak under low-wind conditions. In contrast, a negative difference of stronger than $-1.5^{\circ} \mathrm{C}$ between SPWAVE and CTRL can be seen during the forced stage (Fig. 7d). The additional cooling was mainly contributed by the wave-induced 1D processes (mixing/ diffusion) and 3D processes (upwelling and horizontal advection). First, compared with the traditional shear turbulence (ST), LT can further strengthen local turbulent mixing in the upper ocean (KC04) through 1D local processes. Second, compared with the Eulerian advection, the Lagrangian advection can further decrease SST near the storm center through nonlocal 3D processes.

To quantitatively investigate which processes contribute to the evident negative SST difference, a third experiment, which includes only the SP (SPONLY), is carried out. Figure 8a shows SST difference between SPONLY and CTRL during the forced stage of Typhoon Haitang. The LT-induced cooling weakened, with a minimum of about $-1^{\circ} \mathrm{C}$ in most typhoon affected regions. Besides LT, the Lagrangian advection of temperature further strengthened the cooling, especially in 

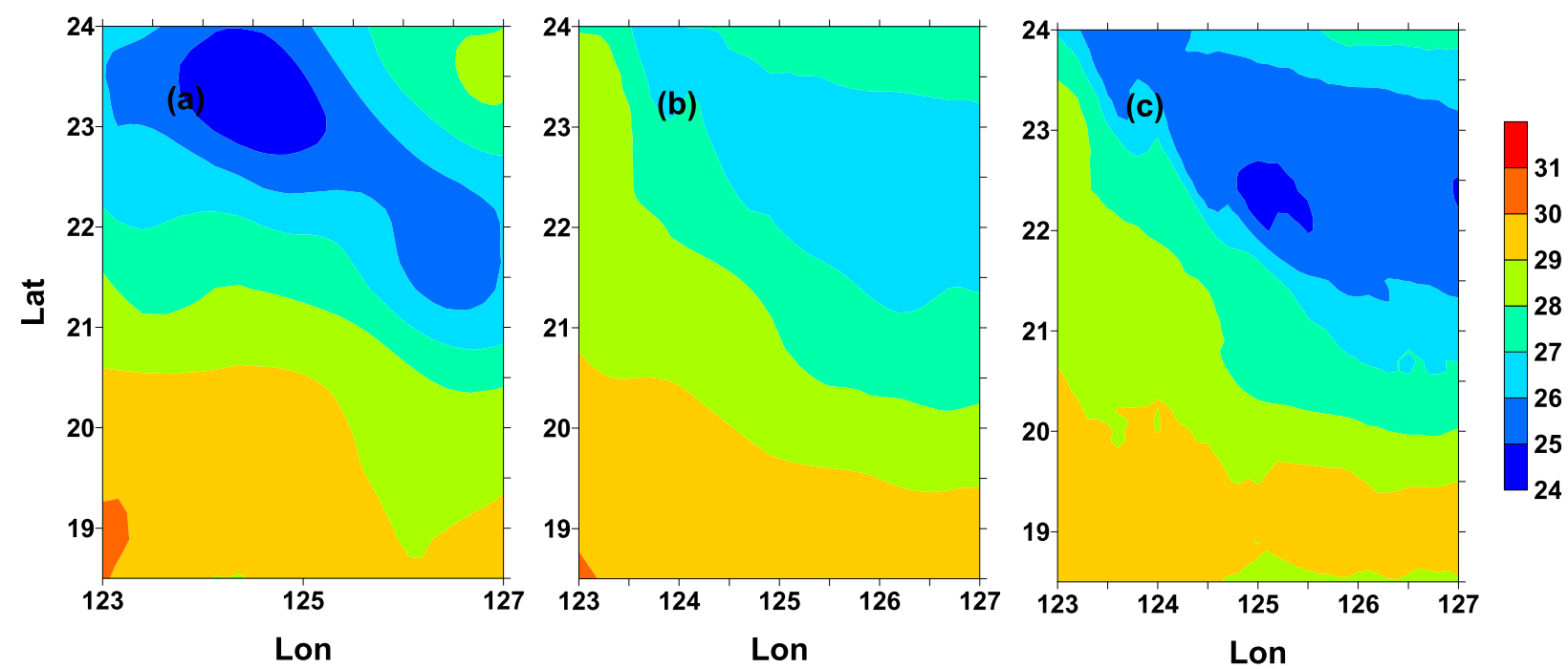

FIG. 9. Horizontal distribution of SST $\left({ }^{\circ} \mathrm{C}\right)$ after typhoon passage from (a) observations, (b) CTRL, and (c) SPWAVE on 20 Jul 2005.

the vicinity of the typhoon center (Fig. 8b). In addition, the Lagrangian advection induced a weak positive SST difference $\left(<0.5^{\circ} \mathrm{C}\right)$ outside of the cooling region. Although the horizontal Eulerian currents were weakened (Zhang et al. 2012; Reichl et al. 2016b) by the inclusion of LT, more heat was advected outward by the Lagrangian currents $\left(U_{L}, V_{L}\right)$ when including the Stokes drift $\left(U_{s}, V_{s}\right)$ than by the Eulerian currents $(U, V)$.
Furthermore, different from the Lagrangian advection of temperature, both CSF and CLVF modulated the horizontal distributions of cooling and warming differences indirectly through the coupling process between momentum and temperature.

Haitang-induced SST cooling persisted for several days after the typhoon had left the study area, which is validated using the daily high-resolution-blended
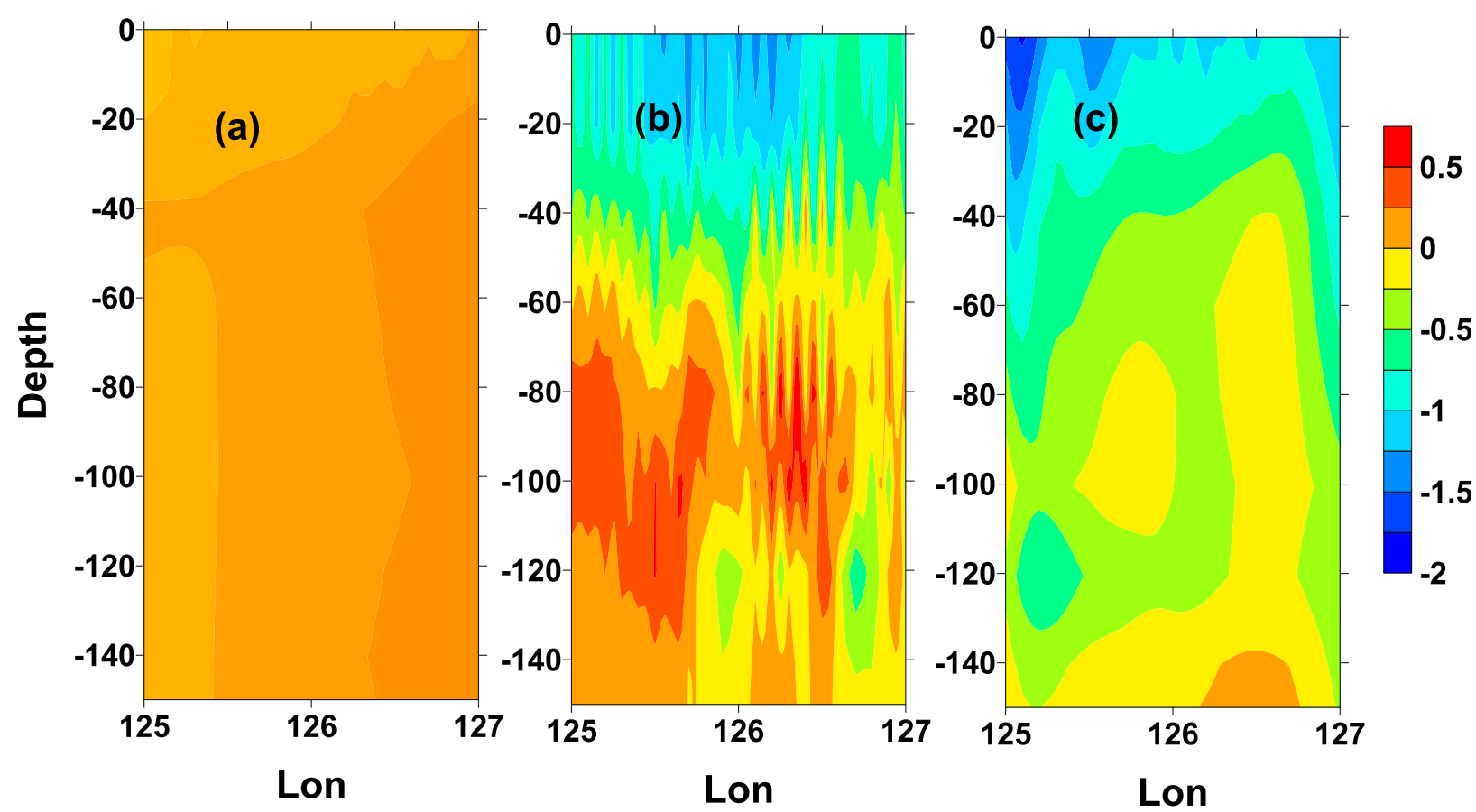

FIG. 10. Temperature difference $\left({ }^{\circ} \mathrm{C}\right)$ in a vertical-zonal section along $21.5^{\circ} \mathrm{N}$ between SPWAVE and CTRL experiments on $(\mathrm{a}) 15$ (pretyphoon stage), (b) 17 (typhoon-forced stage), and (c) 20 Jul 2005 (prerelaxation stage). 
analysis of SST (Reynolds et al. 2007) on a horizontal resolution of $0.25^{\circ} \times 0.25^{\circ}$ on 20 July 2005 (Fig. 9a). The SST patterns from both CTRL (Fig. 9b) and SPWAVE (Fig. 9c) are quite consistent with the analysis, with the results in SPWAVE showing stronger cooling and being closer to the observation. The extra cooling remained after the passage of the typhoon also indicates that LT modulated not only the local SST change on the synoptic time scale but also the overall heat budget on the monthly and seasonal scales.

Temperature difference between SPWAVE and CTRL in the vertical-zonal section along $21.5^{\circ} \mathrm{N}$ is small (less than $0.2^{\circ} \mathrm{C}$ ) in the upper-150-m depth in the pretyphoon stage (Fig. 10a). During the supertyphoon stage of Haitang, the negative difference was larger than $-1.0^{\circ} \mathrm{C}$ near the surface, and the positive difference was greater than $0.5^{\circ} \mathrm{C}$ at the subsurface (Fig. 10b). The temperature difference in Fig. 10b suggests that LT induced an extra enhancement of TKE in the upper layer, which was responsible for transferring more heat from the upper layer to a deeper layer. After Haitang had left the study region on 20 July (Fig. 10c), the positive difference in the thermocline became weaker while the negative difference in the mixed layer became stronger compared to those in Fig. 10b, indicating a warming trend in the mixed layer after the passage of the typhoon was slower when LT was considered.

The SST anomaly was the SST change relative to its value at 0000 UTC 15 July 2005 (pretyphoon stage). Temporally varying horizontally averaged SST anomaly in the area $\left(20^{\circ}-24^{\circ} \mathrm{N}, 123^{\circ}-127^{\circ} \mathrm{E}\right)$ represented overall surface cooling due to Haitang's passage (Fig. 11a). It was near zero within $30 \mathrm{~h}$ (pretyphoon stage), rapidly decreased to $-3^{\circ} \mathrm{C}$ from 30 to $60 \mathrm{~h}$ (typhoon-forced stage), and slowly increased to $-1.6^{\circ} \mathrm{C}$ in CTRL (red) and to $-2.4^{\circ} \mathrm{C}$ in SPWAVE (black). The result in SPWAVE is closer to the observation than that in CTRL. The time series of horizontally averaged mixed layer depth (MLD) in $\left(20^{\circ}-24^{\circ} \mathrm{N}, 123^{\circ}-127^{\circ} \mathrm{E}\right)$ is presented in Fig. 11b. The MLD was about $20 \mathrm{~m}$ deeper in SPWAVE than in CTRL (black vs red in Fig. 11b) after 1200 UTC 17 July 2005 (i.e., $60 \mathrm{~h}$ ). In this study, the MLD is determined using temperature difference criterion $\left(0.5^{\circ} \mathrm{C}\right)$ from the surface. Blair et al. (2017) reported that LT can modify the SST cooling by up to $0.5^{\circ}-0.7^{\circ} \mathrm{C}$ and the MLD by up to $20 \mathrm{~m}$ during typhoon passage. Therefore, the differences in SST and MLD in this study seem to be reasonable.

As we know, the weakness of MY-type turbulence models come from the underestimation of vertical mixing under strong stable stratification, which results in underestimated MLD with an overestimated SST. To correct these biases, several turbulent closure constants
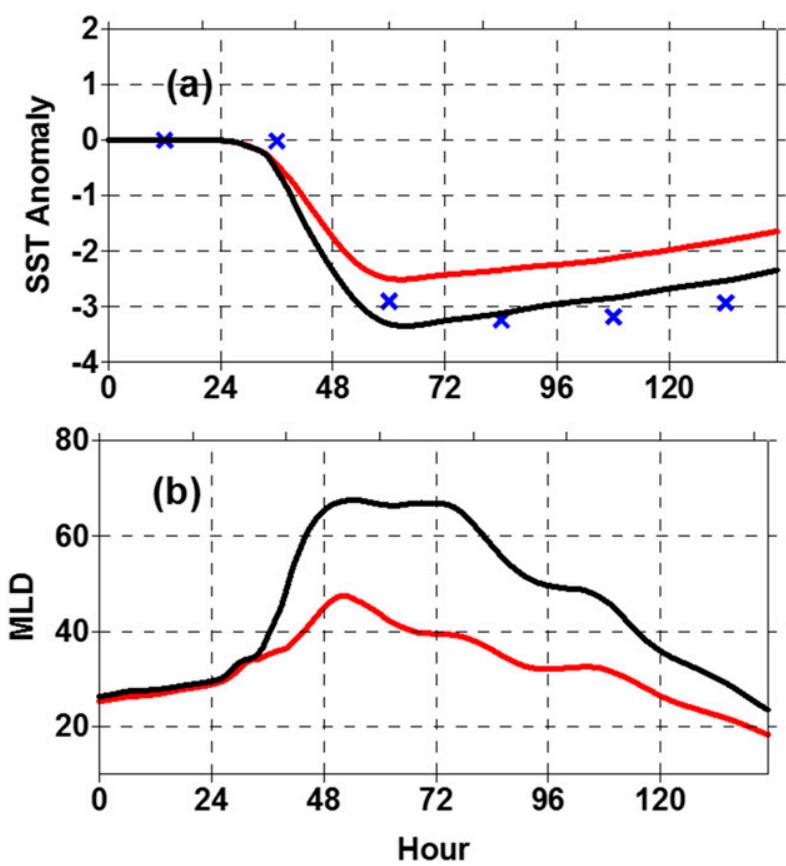

FIG. 11. Time series of horizontally averaged (a) SST anomaly $\left({ }^{\circ} \mathrm{C}\right)$ and (b) mixed layer depth (m) from observations (blue cross), CTRL (red curve), and SPWAVE (black curve) from 15 to 20 Jul 2005. Horizontal axis represents the hour relative to 0000 UTC 15 Jul 2005. SST anomaly is relative to the SST at 0000 UTC 15 Jul 2005.

are modified by updating the expressions for pressurevelocity and pressure-temperature correlations (Cheng et al. 2002; Kantha 2003), which can increase the upper MLD through increasing the critical gradient Richardson number from a value of 0.19 in the original MY model to 1.0. The modification can correct the warm SST bias to some degree, but the underestimation of MLD still exists in state-of-the-art ocean models (Belcher et al. 2012). The problem cannot be resolved until the wave-induced mixing (especially the nonbreaking-wave-induced mixing) is incorporated into the ocean model (KC04; Qiao et al. 2004; Huang and Qiao 2010; Kantha et al. 2010). For evaluating LT-affected modeling performance under the supertyphoon, vertical temperature profiles from CTRL and SPWAVE are compared against the Argo observations at $\left(22.98^{\circ} \mathrm{N}, 123.87^{\circ} \mathrm{E}\right)$ on 17 July 2005 (Fig. 12a) and at $\left(25.97^{\circ} \mathrm{N}, 126.15^{\circ} \mathrm{E}\right)$ on 16 July 2005 (Fig. $12 \mathrm{~b}$ ) during the passage of Haitang. The simulated upper-ocean $(0-40 \mathrm{~m})$ temperature profiles were about $0.5^{\circ} \mathrm{C}$ cooler and closer to the Argo observations (blue) in SPWAVE (black) than in CTRL (red), which indicates an additional cooling with deeper MLD when the LT is added in SPWAVE. However, the simulated temperature profiles below $40-\mathrm{m}$ depth at $\left(25.97^{\circ} \mathrm{N}, 126.15^{\circ} \mathrm{E}\right)$ on $16 \mathrm{July}$ 2005 began to converge gradually to $26^{\circ} \mathrm{C}$ between 

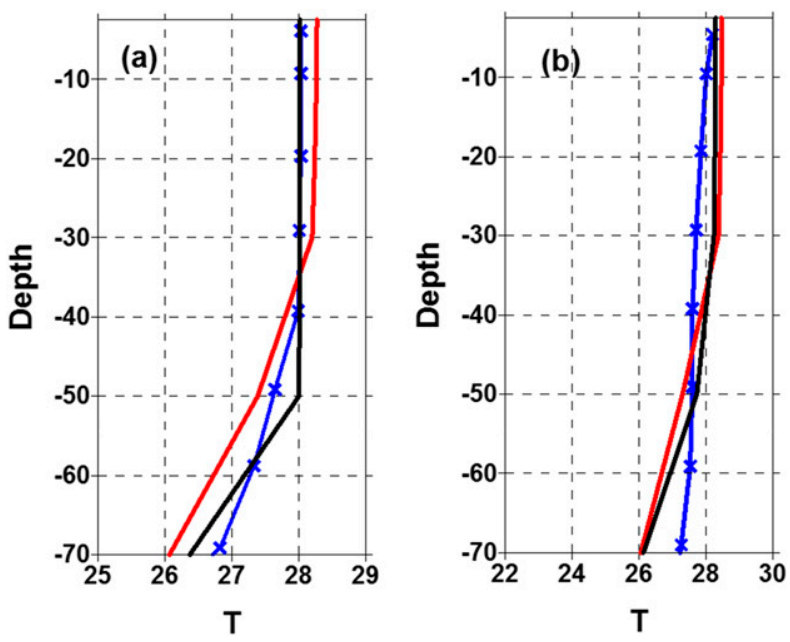

FIG. 12. Vertical temperature profiles from Argo observations (blue; the cross indicates the depth of observations), CTRL (red), and SPWAVE (black) at (a) $\left(22.98^{\circ} \mathrm{N}, 123.87^{\circ} \mathrm{E}\right)$ on $17 \mathrm{Jul} 2005$ and (b) $\left(25.97^{\circ} \mathrm{N}, 126.15^{\circ} \mathrm{E}\right)$ on $16 \mathrm{Jul} 2005$.

SPWAVE and CTRL, which was nearly $1.0^{\circ} \mathrm{C}$ cooler than the observation (Fig. 12b).

Responses of typhoon-induced "heat pump" and "cold suction" to LT at the surface, subsurface, thermocline, and deep ocean are explored here. In this study, we use "heat pump" for the 1D process that strong deep mixing induced by typhoon pumps the surface heat downward to the base of the mixed layer, entering the thermocline. The "cold suction" in this study is referred to the upwelling, which is a $3 \mathrm{D}$ physical process associated with the Ekman pumping owing to the strong wind stress curl generated by the typhoon. The location $\left(21.5^{\circ} \mathrm{N}, 125.5^{\circ} \mathrm{E}\right)$ was under the Haitang eye at 0000 UTC 17 July. Since then, the time series of simulated temperature at several depths of this location showed cooling effect during Haitang's passage (Fig. 13). At the sea surface, the simulated temperature was nearly the same from 0 to $30 \mathrm{~h}$ between CTRL and SPWAVE, was cooler in SPWAVE than in CTRL after $30 \mathrm{~h}$, and then warmed up slightly afterward (Fig. 13a), indicating the heat pump process was strengthened when LT was considered. In the subsurface (50-m depth), the temperatures in CTRL and SPWAVE (Fig. 13b) were nearly the same in the pretyphoon stage. After that, a sudden warming occurred from 36 to $40 \mathrm{~h}$ owing to the effect of typhoon-induced heat pump. Subsequently, temperature decreased rapidly from 40 until $60 \mathrm{~h}$, with a stronger cooling in CTRL (red) than in SPWAVE (black). At $60 \mathrm{~h}$, the mixed layer was deeper than $50 \mathrm{~m}$ in SPWAVE but shallower than $50 \mathrm{~m}$ in CTRL. Therefore, typhoon-induced cold suction below the mixed layer contributed to the larger cooling in CTRL, indicating the cold suction process was inhibited by LT. In the thermocline (125-m depth), temperature was slightly warmer in SPWAVE than in CTRL after $60 \mathrm{~h}$ (Fig. 13c), which indicates more heat from the upper layer was brought into the thermocline via LT after the typhoon passage. In the deep ocean (1000-m depth), temperature was almost the same between SPWAVE and CTRL (Fig. 13d), which indicates the effect of the LT was absent there. Temporal variations of temperature in
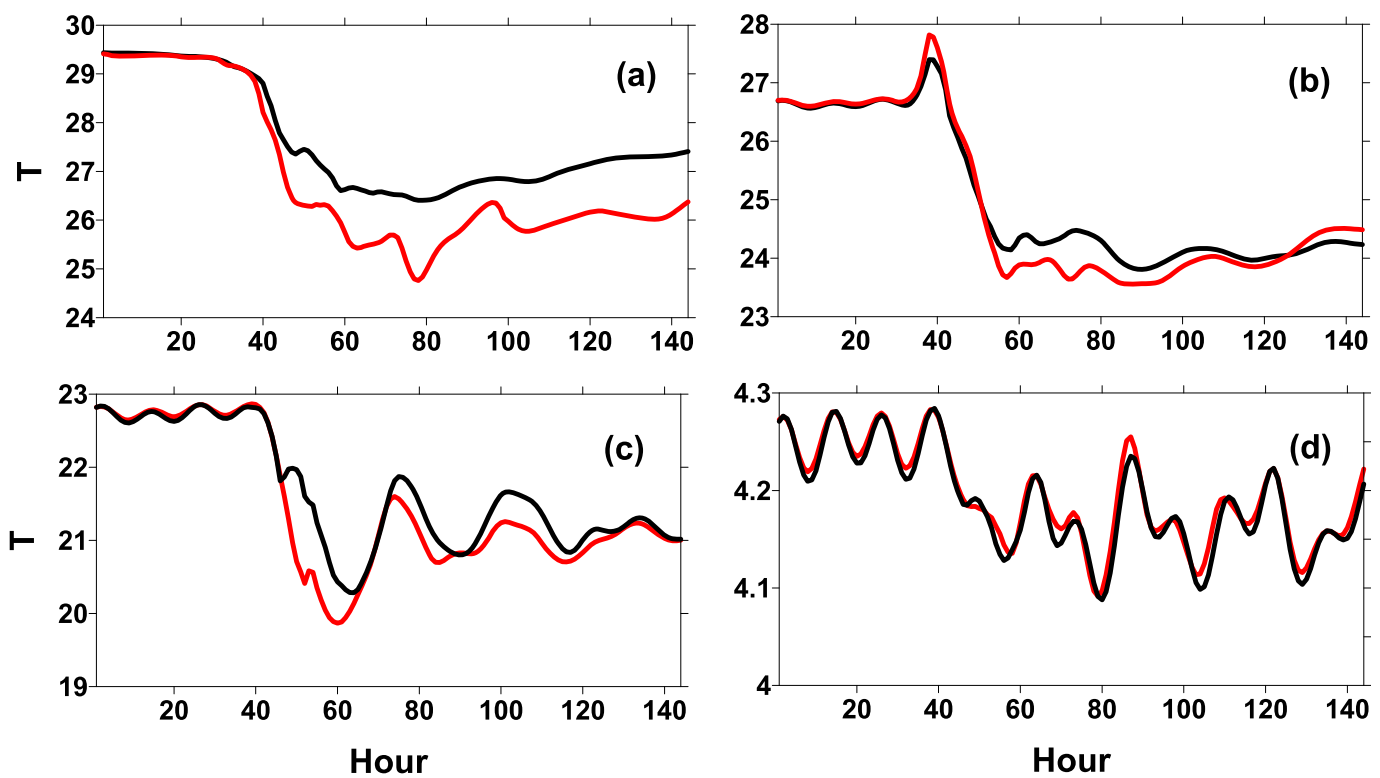

FIG. 13. Time series of temperature at $\left(21.5^{\circ} \mathrm{N}, 125.5^{\circ} \mathrm{E}\right)$ at (a) the sea surface, (b) 50 , (c) 125 , and (d) $1000 \mathrm{~m}$ in CTRL (red) and SPWAVE (black). The horizontal axis represents the hour relative to 0000 UTC 15 Jul 2005. 
CTRL and SPWAVE showed that the regular tides with an amplitude of about $0.05^{\circ} \mathrm{C}$ was obvious before the typhoon passage, rapidly decreased from $4.3^{\circ}$ (at $30 \mathrm{~h}$ ) to $4^{\circ} \mathrm{C}$ (at $54 \mathrm{~h}$ ), that is, after the arrival of Haitang, and changed to near-inertial oscillations with an amplitude of $0.1^{\circ} \mathrm{C}$ after $54 \mathrm{~h}$.

Changes of vertical temperature profiles (Fig. 14) at the same location of $\left(21.5^{\circ} \mathrm{N}, 125.5^{\circ} \mathrm{E}\right)$ from 0000 (dashed) and 1200 UTC 17 July (solid) were simulated in both CTRL (red) and SPWAVE (black). During the typhoon passage, LT deepened the mixed layer (black versus red), reinforced the heat pump with higher temperature at the base of the mixed layer, and induced the cold suction with top-to-bottom unified cooling, as shown by the comparison between SPWAVE and CTRL. The unified cooling showed that the heat was not conserved in the temperature profile, indicating the upwelling process dominated the ocean dynamics in the whole upper layer of the ocean because of the Ekman pumping associated with the typhoon-induced strong wind stress curl.

\section{Diagnostic analysis results}

\section{a. Local momentum balance during typhoon-forced stage}

A diagnostic analysis of the zonal momentum balance at the sea surface is carried out to investigate the contributions of CSF and CLVF to the momentum budget during the forced stage of Haitang in SPWAVE, which occurred at 0000 UTC 17 July. The Coriolis force $-f V$ had a dipole pattern with stronger negative (weaker positive) core on the right-hand (left hand) side of the typhoon track (Fig. 15a). A similar pattern of $\mathrm{CSF}_{x}$ (i.e., $-f V_{s}$ ) as that of the Coriolis force (see Fig. 15b) indicates its modulation of the momentum balance in the $x$ direction locally, together with the Coriolis force. The cyclonic CSF increased the divergent storm-induced current to enhance the upwelling of cold water to some degree (Reichl et al. 2016a), which contributed to the total SST cooling together with LT and the Lagrangian advection of temperature. In addition, the Eulerian advection affected the momentum budget obviously (Fig. $15 \mathrm{c}$ ). The $\mathrm{CLVF}_{x}$ term had an evident contribution to the momentum balance in the region with large relative vorticity (Fig. 15d). The spatial scale in the CLVF $F_{x}$ term was smaller than those in the $\mathrm{CSF}_{x}$ and Coriolis terms.

\section{b. Quasigeostrophy during typhoon's passage}

While the geostrophic balance was broken during the forced stage of Haitang, the typhoon-induced quasigeostrophy could be established and maintained during and after the typhoon. Figure 16 shows the time series of horizontally averaged nondimensional surface pressure

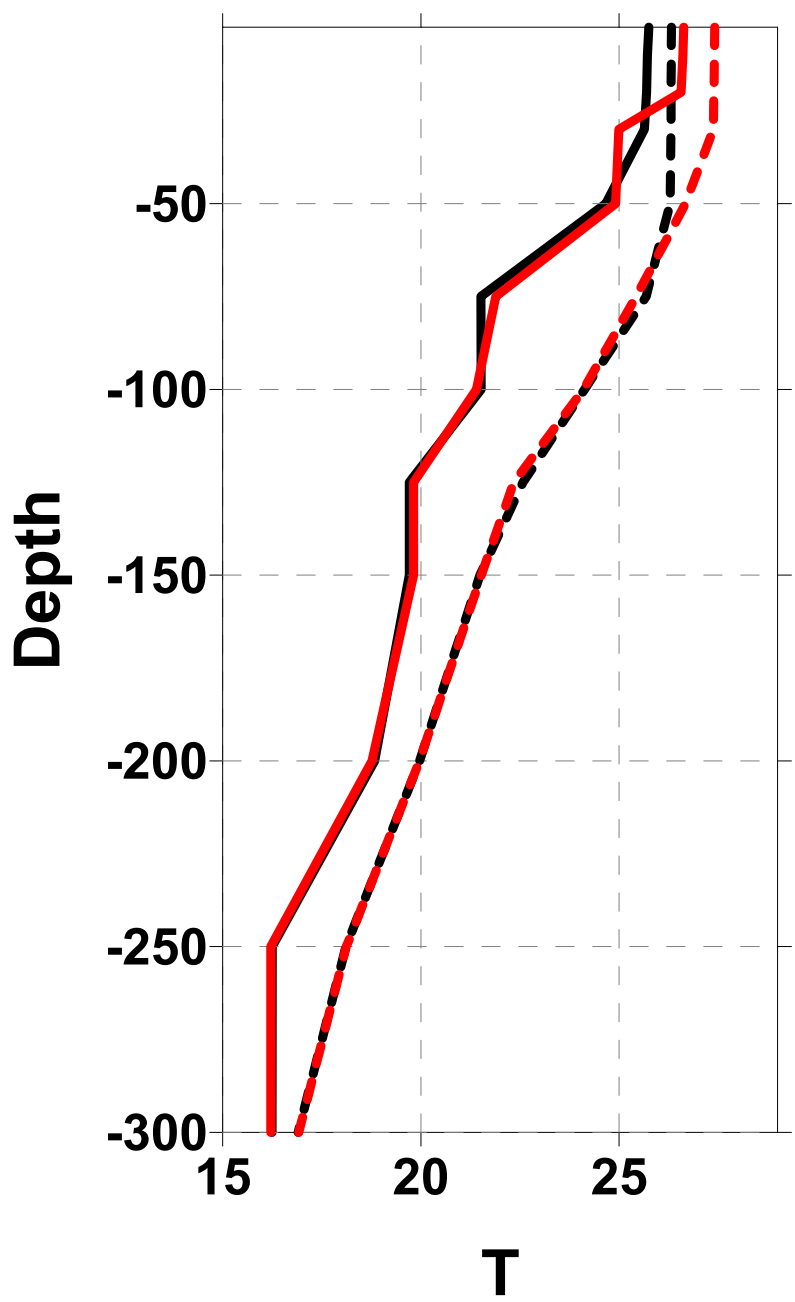

FIG. 14. Vertical temperature profiles at $\left(21.5^{\circ} \mathrm{N}, 125.5^{\circ} \mathrm{E}\right)$ in CTRL (red) and SPWAVE (black) at 0000 UTC 17 Jul 2005 (dashed) and at 1200 UTC 17 Jul 2005 (solid).

gradient forcing $\left|g s_{0} \nabla \eta\right|$ (purple), $|\mathbf{C S F}|$ (black), advection (red), and $|\mathbf{C L V F}|$ (blue) normalized by the magnitude of the Coriolis force $|2 \boldsymbol{\Omega} \times \mathbf{U}|$ from 16 to 18 July 2005 . The $\boldsymbol{\Omega}$ is the earth's rotation vector. The geostrophy with tidal oscillation on 16 July (before $24 \mathrm{~h}$ ) broke down because $\left|g s_{0} \nabla \eta\right| /|2 \boldsymbol{\Omega} \times \mathbf{U}|$ (purple) reduced rapidly from 0.7 at 0000 UTC 17 July ( $24 \mathrm{~h}$ ) to 0.3 at 0800 UTC 17 July ( $32 \mathrm{~h}$ ) and was then reduced slightly until $48 \mathrm{~h}$; after that, the geostrophic balance tended to be reestablished. The Rossby number, $\mid$ advection $|/| 2 \boldsymbol{\Omega} \times \mathbf{U} \mid$ (red), gradually increased from near zero at 0000 UTC to a maximum of 0.16 at 0800 UTC 17 July; it then slowly decreased to 0.1 at 2400 UTC 17 July ( 48 h). After 48 h, the Rossby number decreased to about 0.1 , representing a quasigeostrophic process. The term $|\mathbf{C S F}| /|2 \mathbf{\Omega} \times \mathbf{U}|$ (black) increased rapidly from near 0.1 to a maximum value of 0.9 at $32 \mathrm{~h}$, remained at a high value, and then 

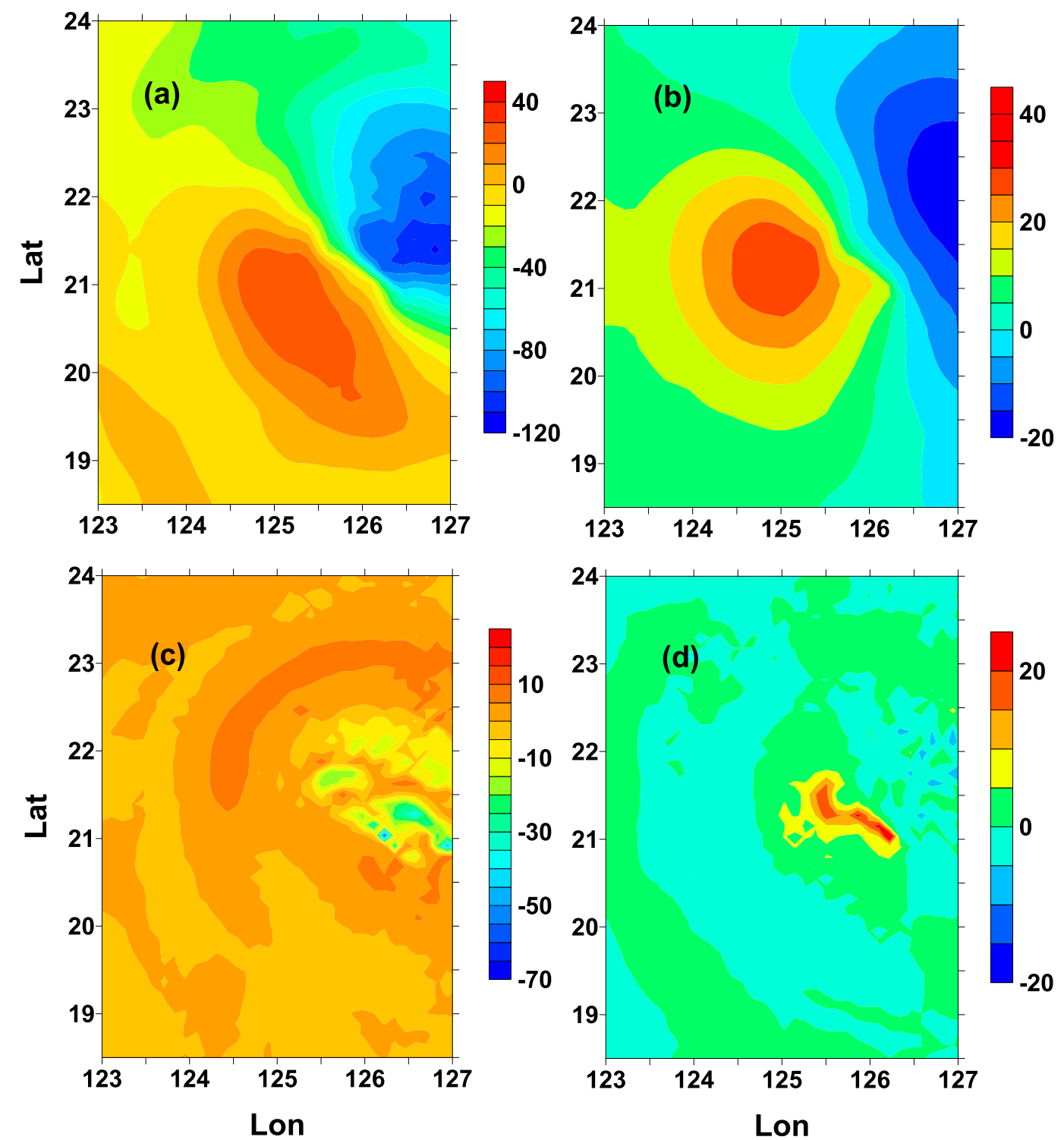

FIG. 15. Surface distribution of the (a) Coriolis force $-f V$, (b) $\mathrm{CSF}_{\boldsymbol{x}}$, (c) advection, and (d) $\mathrm{CLVF}_{x}\left(10^{-6} \mathrm{~m} \mathrm{~s}^{-2}\right)$ from the zonal momentum equation [Eq. (4)] on $17 \mathrm{Jul} 2005$.

monotonically decreased to 0.36 until $48 \mathrm{~h}$. The term $|\mathbf{C L V F}| /|2 \boldsymbol{\Omega} \times \mathbf{U}|$ also contributed to the quasigeostrophy and had a similar pattern of the term $\mid$ advection $|/| 2 \mathbf{\Omega} \times \mathbf{U} \mid$ (blue versus red); the value at the forced stage was $60 \%$ smaller than the corresponding Rossby number.

c. $T K E$

The shear production term $P_{q^{2}}$ in Eq. (9) depends on the correlation between turbulent flux and the gradient of $\mathbf{U}_{s}$, which indicates that the turbulent flux can count against the Stokes drift gradient (Sullivan et al. 2012). To investigate the effect of LT on the countergradient turbulent flux under Supertyphoon Haitang, the shear production term in Eq. (12) including both ST and LT is reorganized as follows:

$$
\begin{aligned}
P_{q^{2}}= & \frac{2}{s_{k}}\left\{K_{M}\left[\left(\frac{\partial U}{\partial k}\right)^{2}+\left(\frac{\partial V}{\partial k}\right)^{2}\right]\right. \\
& +\left(K_{M}+K_{M S}\right)\left(\frac{\partial U}{\partial k} \frac{\partial U_{s}}{\partial k}+\frac{\partial V}{\partial k} \frac{\partial V_{s}}{\partial k}\right) \\
& \left.+K_{M S}\left[\left(\frac{\partial U_{s}}{\partial k}\right)^{2}+\left(\frac{\partial V_{s}}{\partial k}\right)^{2}\right]\right\} .
\end{aligned}
$$

The first term in the brackets of Eq. (23) presents the Eulerian shear production term, which is contributed by 


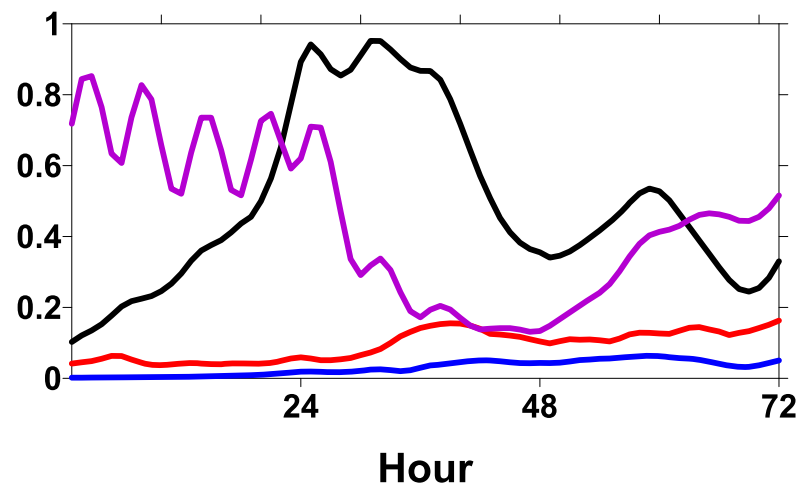

FIG. 16. Time series of horizontally averaged nondimensional surface pressure gradient forcing $\left|g s_{0} \nabla \eta\right|$ (purple), $|\mathbf{C S F}|$ (black), advection (red), and $|\mathbf{C L V F}|$ (blue) from 16 to $18 \mathrm{Jul} 2005$. All terms are normalized by the magnitude of the Coriolis force $|2 \Omega \times \mathbf{U}|$. The horizontal axis represents the hour relative to 0000 UTC 16 Jul 2005.

the conventional ST, and the third term is the SP term when LT is considered. The $K_{M}$ and $K_{M S}$ represent ST-related and LT-related mixing coefficients, respectively. The middle term in the parentheses is the crossed term between Eulerian shear production and SP, showing the correlation between ST and LT. Under the condition of wind-wave equilibrium, the downgradient of $\mathbf{U}_{s}$ and downgradient of $\mathbf{U}$ are positively correlated. Under the misalignment between wind and wave fields, the two terms are uncorrelated or negatively correlated.
The intersection angle of the two vectors $\partial \mathbf{U} / \partial z$ and $\partial \mathbf{U}_{s} / \partial z$ at 0000 UTC 17 July remained small in the foreside region of the typhoon and became obviously large within the eye and in the rear of the typhoon (Fig. 17a). The direction cosine of the two vectors (Fig. 17b) indicated an obvious effect of the wind-wave misalignment on the countergradient turbulent flux in the rear quadrant region of the typhoon. The opposing swell dominates in the rear of the typhoon (Holthuijsen et al. 2012), being responsible for the visible countergradient over there. Figure 18a presents the horizontal distribution of $P_{q^{2}}$ at 5-m depth in the two low-value regions. The first one coincided with the position of the wind-wave misalignment region shown in Fig. 17b. The second one was in the maximum wind speed region on the right-hand side of the typhoon moving track, where both drag coefficient $C_{d}$ (red in Fig. 19) and wind stress (blue in Fig. 19) were reduced dramatically when the wind speed surpassed $60 \mathrm{~m} \mathrm{~s}^{-1}$. Blair et al. (2017) noted that different choices of drag coefficient make it difficult to draw any conclusion regarding whether a given LT parameterization improves the upper-ocean model predictions or not. The wave model may in fact compensate for the choice of drag coefficient. Since wind speeds under the supertyphoon are far beyond any reliable observations, there should be a lot of freedom for this choice, the effect of which can be removed through normalizing the production term. To better explore the effect of the countergradient turbulent flux on the $P_{q^{2}}$, the shear production term is normalized by $u_{\tau}^{3} / H$ to
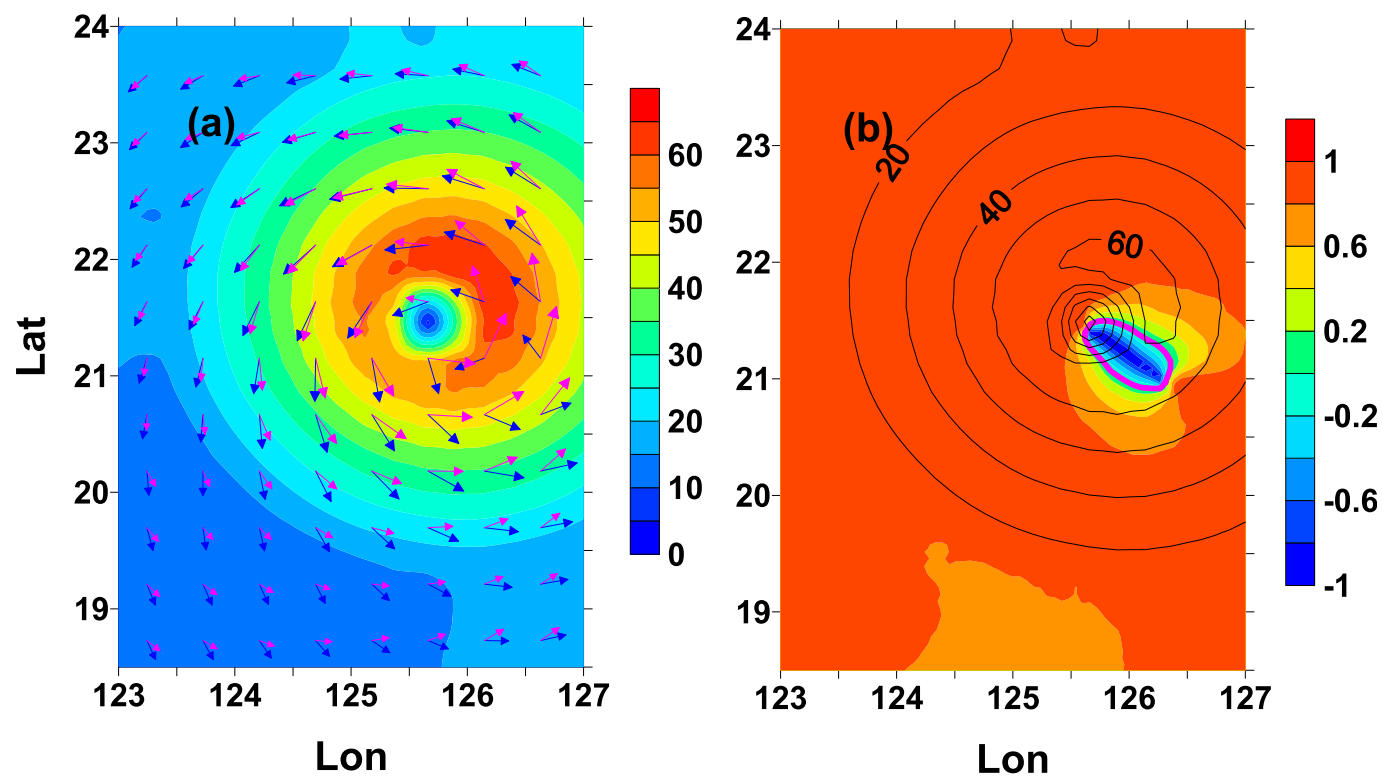

FIG. 17. (a) Downgradient $\mathbf{U}$ (pink arrows) and $\mathbf{U}_{s}$ (blue arrows) and (b) direction cosine of the two vectors at 0000 UTC 17 Jul 2005. Shadings in (a) and contours in (b) show the typhoon wind speed. 

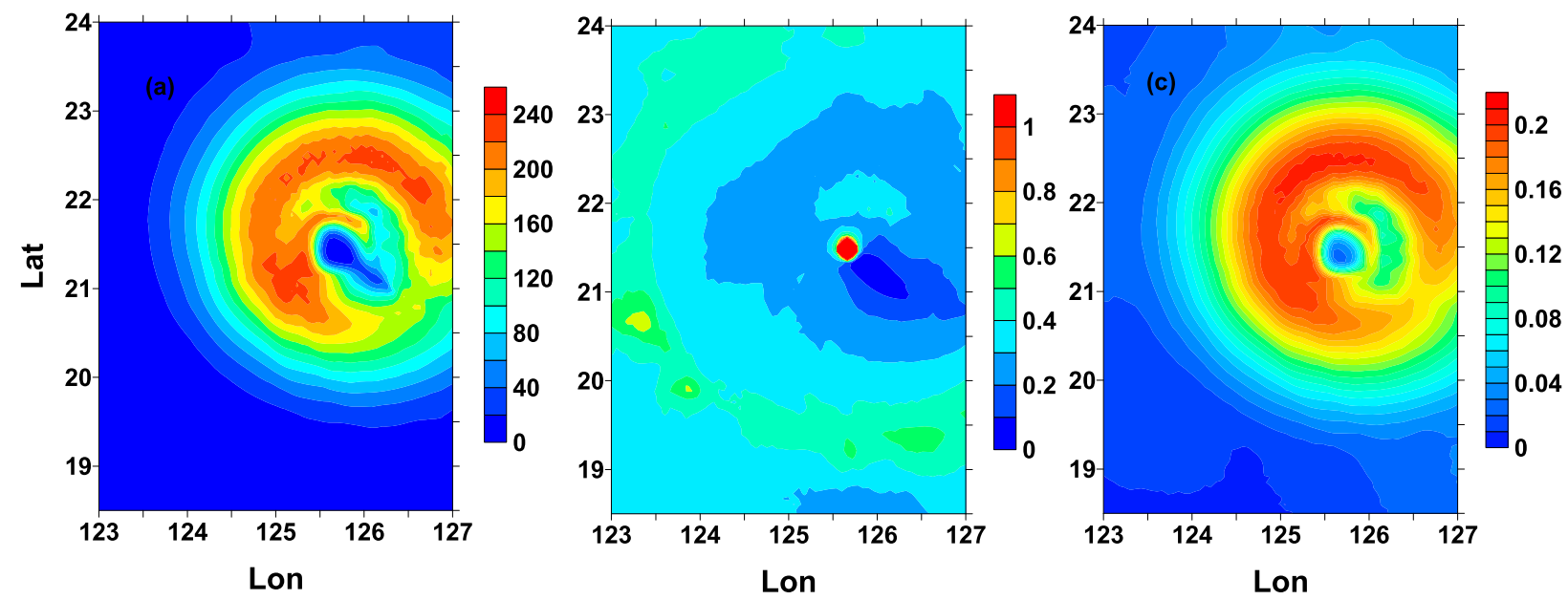

FIG. 18. Horizontal distribution of (a) shear production $P_{q^{2}}$ at $5-\mathrm{m}$ depth $\left(10^{-6} \mathrm{~m}^{2} \mathrm{~s}^{-3}\right)$, (b) shear production normalized by $u^{* 3} / H(H$ here is $5 \mathrm{~m})$, and (c) twice the TKE $q^{2}\left(\mathrm{~m}^{2} \mathrm{~s}^{-2}\right)$ during the forced stage of typhoon at 0000 UTC $17 \mathrm{Jul} 2005$.

remove the feature of $C_{d}$. As can be seen from Fig. 18b, LT can be severely suppressed to a low level in the rear of the typhoon. The pattern of the shear production term including LT determined the pattern of $q^{2}$ (Fig. 18c), and the low-value regions were consistent between $q^{2}$ and $P_{q^{2}}$. Therefore, once the wind speed reached certain strength (more than $60 \mathrm{~m} \mathrm{~s}^{-1}$ or so) under the condition of the supertyphoon, LT would lose the traditional right-reinforced structure due to the specific characteristics of the drag coefficient (red) and wind stress (blue) shown in Fig. 19. Rabe et al. (2015) suggested that the drag coefficient uncertainty in high wind is a key factor influencing the difference between observed and simulated VVV. A low value $C_{d}$ of 0.0014 still cannot simulate the low VVV in the observation in the wind-wave misalignment regions, indicating that a lower value $C_{d}$ (lower than 0.0014 ) is likely needed to simulate the suppression of $q^{2}$. In addition, we have no evidence that the wind stress (not just $C_{d}$ ) should actually decrease with increasing wind speed, as Fig. 19 shows. Generally, a constant $C_{d}$ is set, so the stress continues to increase with wind speed. However, we suggest that if the characteristics of both $C_{d}$ and wind stress are employed, it has the potential to simulate the suppression of $q^{2}$.

Horizontal distributions of vertical turbulent eddy viscosity $K_{M}$ and $K_{M S}$, derived from SPWAVE at the typhoon-forced stage, are shown in Figs. 20a and 20b, respectively. Low-value regions in $K_{M}$ and $K_{M S}$ (Fig. 20), consistent with those in $q^{2}$ and $P_{q 2}$ (Fig. 18), indicate that the wind-wave misalignment (enough high wind speed) could distinctly suppress LT (ST) mixing to a low level. Because of the inclusion of LT mixing, $K_{M}$ in SPWAVE was larger than that in CTRL in most typhoon-forced regions (see Fig. 20c). The evident positive difference of $K_{M}$ within the eye indicates that the wave rather than the wind dominated the turbulent production due to the low wind speed there. A negative difference region was behind the eye along the typhoon's moving direction, due to the suppressed LT by the misalignment mentioned above. The difference of $P_{q^{2}}$ between CTRL and SPWAVE at the typhoonforced stage is presented in Fig. 20d. Compared to ST, LT enhanced (suppressed) the turbulent mixing in the wind-wave equilibrium (the wind-wave misalignment) regions, which is consistent with the LES results of Sullivan et al. (2012), indicating the misaligned windwave state could be a sink of TKE owing to the countergradient between vertical turbulent flux and down the Stokes drift gradient. Besides the wind-wave misalignment, Sullivan et al. (2012) indicated that the

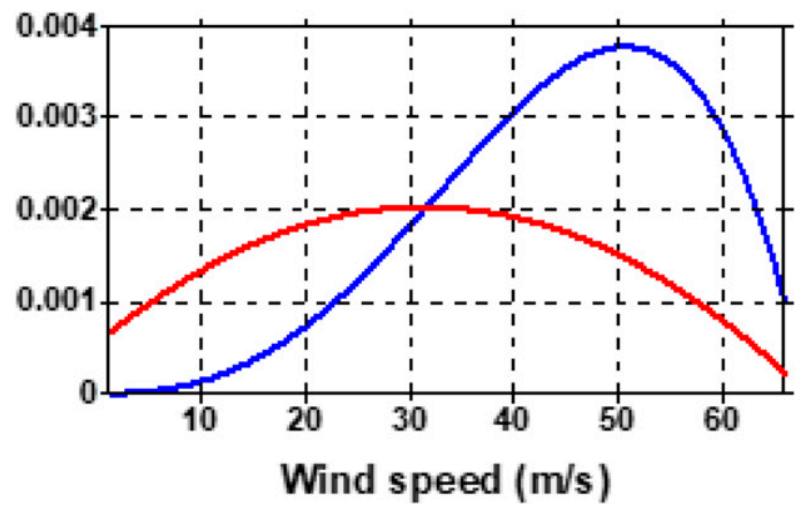

FIG. 19. Changes of (a) wind drag coefficient (red) and (b) wind stress (blue) with the wind speed, based on the drag coefficient parameterization of Zijlema et al. (2012). 

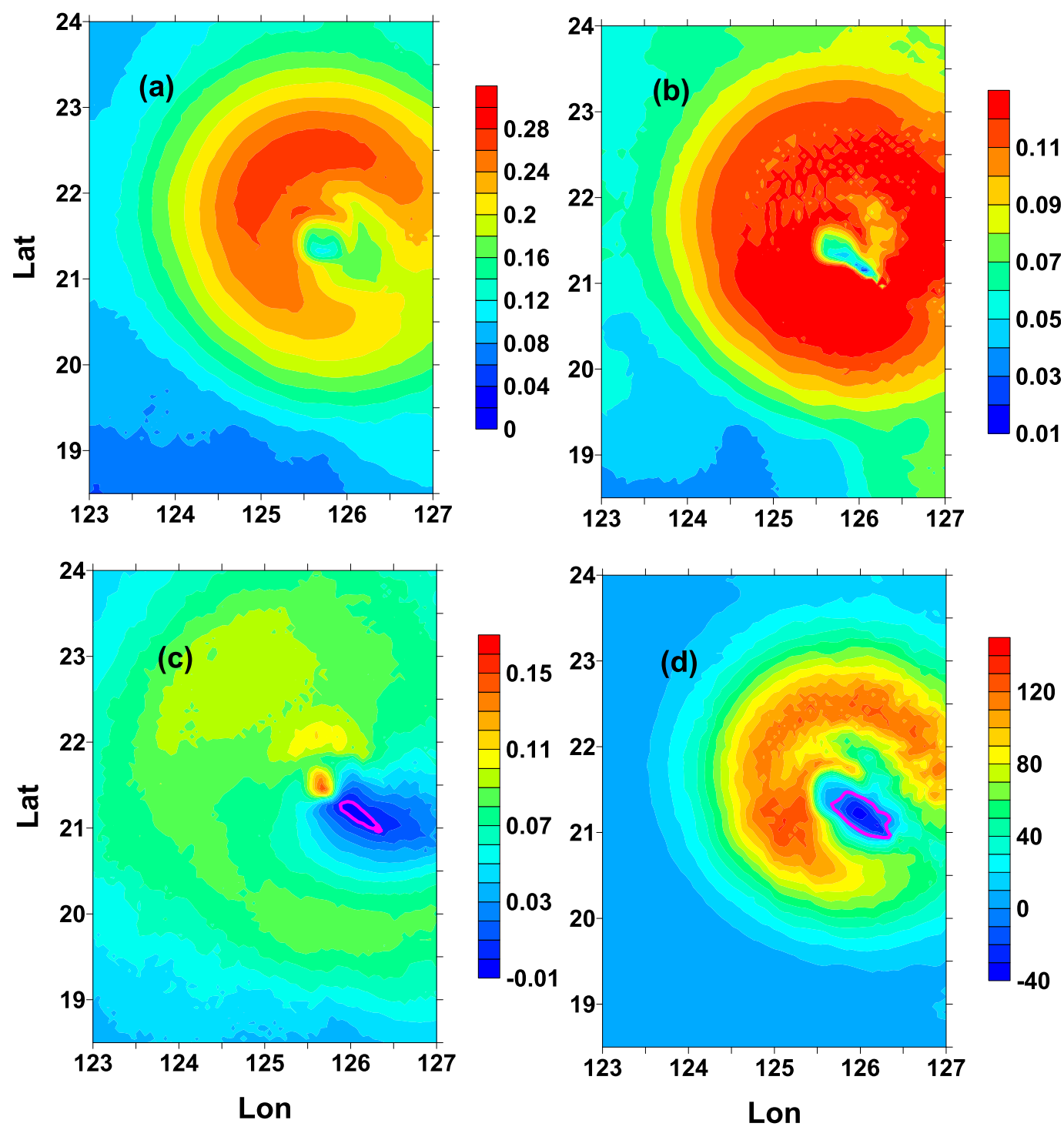

FIG. 20. Horizontal distributions of vertical turbulent eddy viscosity (a) $K_{M}$ and (b) $K_{M S}$ in SPWAVE and difference of (c) $K_{M}\left(\mathrm{~m}^{2} \mathrm{~s}^{-1}\right)$ and (d) shear production $P_{q^{2}}\left(10^{-6} \mathrm{~m}^{2} \mathrm{~s}^{-3}\right)$ between SPWAVE and CTRL during the forced stage of typhoon at 0000 UTC 17 Jul 2005.

turbulent Langmuir number $L_{n}$ and the ratio of the Stokes profile depth (not the $e$-folding depth) to MLD also contributed to the potency of LT. We do not discuss $L_{n}$ here because there is no robust definition of $L_{n}$ when wind and wave remain severely misaligned. The effect of the Stokes profile depth on entrainment will be investigated during supertyphoon conditions based on the results of Sullivan et al. (2012) in future study.

\section{d. Wave breaking under the supertyphoon}

It is known that wave-breaking-induced mixing can only be restricted to the top few meters near the ocean surface under low or middle wind conditions. We want to know whether the breaking waves have the potential to penetrate deeper under the supertyphoon. To investigate the effects of wave breaking and LT on the TKE under the supertyphoon, two more simulations, SPWAVE_noLT and SPWAVE_nobreaking, are carried out in this study; both are the same as SPWAVE except for wave breaking or LT being absent, respectively. Figures $21 \mathrm{a}-\mathrm{c}$ show the vertical distributions of $q^{2}$ along $21.5^{\circ} \mathrm{N}$ in SPWAVE, SPWAVE_noLT, and SPWAVE_nobreaking on 17 July 2005. The low-value region between $125^{\circ}$ and $126^{\circ} \mathrm{E}$ in Fig. 20a coincided with the location of the typhoon eye (weak wind), and the second low-value region between $126^{\circ}$ and $127^{\circ} \mathrm{E}$ 

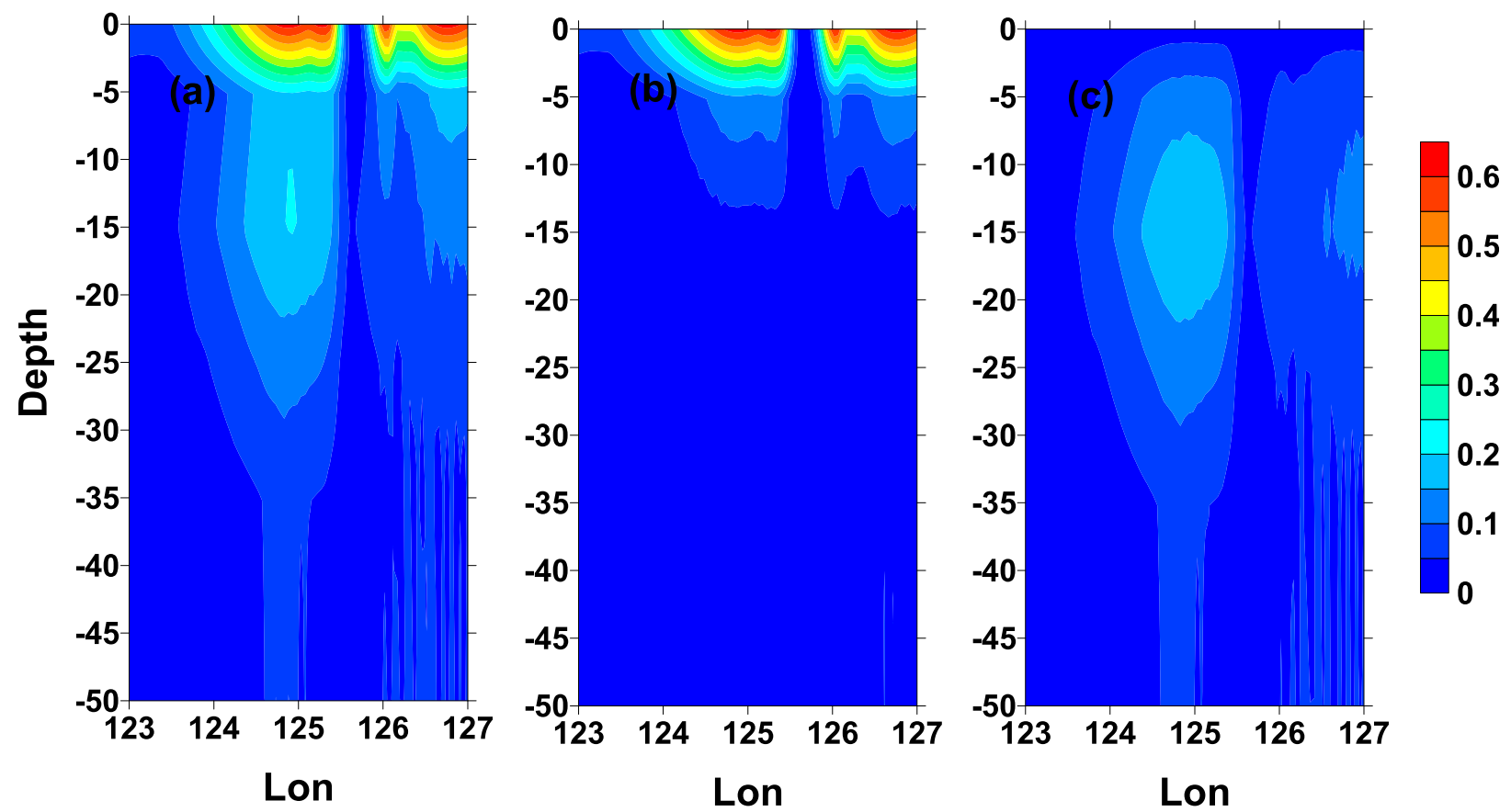

FIG. 21. Vertical distributions of $q^{2}$ along $21.5^{\circ} \mathrm{N}$ in (a) SPWAVE, (b) SPWAVE_noLT, and (c) SPWAVE_nobreaking on 17 Jul 2005.

was under high wind speed $\left(>60 \mathrm{~m} \mathrm{~s}^{-1}\right)$. Both maximum values of $q^{2}$ from SPWAVE and SPWAVE_noLT reached $0.6 \mathrm{~m}^{2} \mathrm{~s}^{-2}$ beyond the typhoon eye region and were caused by the inclusion of the Craig-Banner boundary condition in the TKE equation. The wall layer approximation in the Craig-Banner boundary condition failed near the sea surface because of the existence of breaking waves. Most TKE injected by breaking waves was dissipated through vertical turbulent diffusion rather than via vertical shear (Drennan et al. 1996; Kitaigorodskii et al. 1983). In addition, comparison of the results between Fig. 21b and Fig. 21c suggests that the LT mixing enhanced TKE in the subsurface layer between 5- and 50-m depths. Figure 22a (Fig. 22b) shows the difference between SPWAVE and SPWAVE_noLT (between SPWAVE and SPWAVE_nobreaking). The LT-enhanced TKE mixed temperature more within the mixed layer and deepened the mixed layer at the forced stage of Supertyphoon Haitang (Fig. 22a). In contrast, the wave-breaking-enhanced TKE could only penetrate the 5-m depth (Fig. 22b), even under the supertyphoon. Therefore, LT played a more prominent role in enhancing turbulent mixing in the entire mixed layer during the supertyphoon's passage. It is worth noting that although the wave breaking itself could not make TKE penetrate deeper, wavebreaking-induced spray process seemed to have a visible contribution to the TKE budget during the passage of the typhoon (Zhang et al. 2017). The impact of sea spray on the upper-ocean thermal structure will be investigated in future study together with LT.

\section{Conclusions}

The 3D POMgcs-SWAN coupled simulation results are used to identify the effect of LT on the thermal structure during the passage of Supertyphoon Haitang (2005) east of the Luzon Strait. The second-moment closure model of LT developed by Harcourt (2015) is employed to investigate the effect of LT on the thermal response of ocean mixed layer in a realistic typhoon scenario. Besides LT, several other Stokes drift-related mechanisms, such as CSF and Lagrangian advection of temperature, are also investigated in this study. In addition, since the resolved-scale CLVF is often neglected, its effect on the momentum budget is explored during the supertyphoon. Compared with the ST, the LT strengthened the "heat pump" in most typhoon-affected regions at the forced stage. An additional SST cooling was induced by both local LT mixing through 1D processes and Lagrangian advection of temperature through $3 \mathrm{D}$ processes near the typhoon center. The geostrophy is broken down during the typhoon's passage, and the CSF had the same order of magnitude as the geostrophic term. During and after the typhoon's passage, the distinct quasigeostrophic process was established and maintained, with visible contribution from the CLVF. The CLVF had the same order of magnitude 

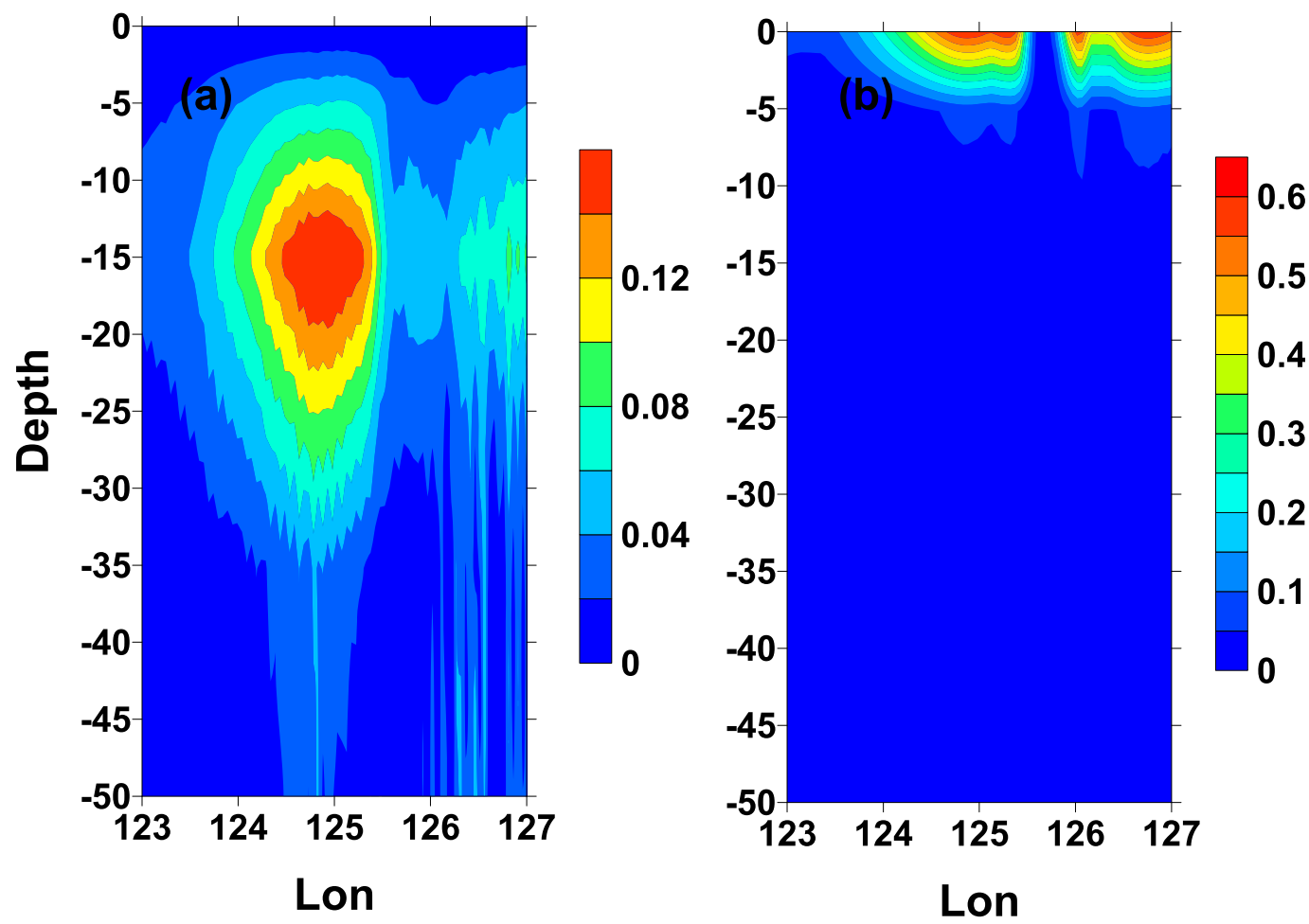

FIG. 22. The $q^{2}$ difference in vertical-zonal section along $21.5^{\circ} \mathrm{N}$ (a) between SPWAVE and SPWAVE_noLT and (b) between SPWAVE and SPWAVE_nobreaking on 17 Jul 2005.

as the horizontal Eulerian advection in the typhooninduced strong-vorticity region, even if its spatial scale was smaller than the CSF and that of the Coriolis force. Through LT mixing, the TKE was more (less) enhanced in wind-wave-aligned (misaligned) regions. In addition, LT was more important than wave breaking within the mixed layer during the forced stage of Supertyphoon Haitang. The effect of the latter was limited near the sea surface even under the supertyphoon condition.

Model errors existed owing to uncertainties such as the coarse horizontal resolution of the heat fluxes and the absence of the vertical component of the vortex forcing term. In future study, spray-induced turbulent flux will be considered together with LT. Further, the upper-ocean near-inertial response to LT during the relaxation stage of typhoon will be explored.

Acknowledgments. This research was jointly supported by grants from the National Key Research and Development Program of China (2017YFC1404103), National Natural Science Foundation of China (41676088 and 41606039), and National Programme on Global Change and Air-Sea Interaction (GASI-01-01-12 and GASI-IPOVAI-04) of China. Peter C. Chu was supported by the U.S. Office of Naval Research.

\section{REFERENCES}

Babanin, A. V., and B. K. Haus, 2009: On the existence of water turbulence induced by nonbreaking surface waves. J. Phys. Oceanogr., 39, 2675-2679, https://doi.org/10.1175/2009JPO4202.1.

Belcher, S. E., and Coauthors, 2012: A global perspective on Langmuir turbulence in the ocean surface boundary layer. Geophys. Res. Lett., 39, L18605, https://doi.org/10.1029/2012GL052932.

Blair, A., I. Ginis, T. Hara, and E. Ulhorn, 2017: Impact of Langmuir turbulence on upper ocean response to Hurricane Edouard: Model and observations. J. Geophys. Res. Oceans, 122, 9712-9724, https://doi.org/10.1002/2017JC012956.

Booij, N., R. C. Ris, and L. H. Holthuijsen, 1999: A thirdgeneration wave model for coastal regions: 1 . Model description and validation. J. Geophys. Res., 104, 7649-7666, https://doi.org/10.1029/98JC02622.

Carniel, S., J. C. Warner, J. Chiggiato, and M. Sclavo, 2009: Investigating the impact of surface wave breaking on modeling the trajectories of drifters in the northern Adriatic Sea during a wind event. Ocean Modell., 30, 225-239, https:// doi.org/10.1016/j.ocemod.2009.07.001.

Carr, L. E., and R. L. Elsberry, 1997: Models of tropical cyclone wind distribution and beta-effect propagation for application to tropical cyclone track forecasting. Mon. Wea. Rev., 125, 3190-3209, https://doi.org/10.1175/1520-0493(1997)125<3190: MOTCWD $>2.0 . \mathrm{CO} ; 2$.

Cheng, Y., V. M. Canuto, and A. M. Howard, 2002: An improved model for the turbulent PBL. J. Atmos. Sci., 59, 1550-1565, https:// doi.org/10.1175/1520-0469(2002)059<1550:AIMFTT>2.0.CO;2.

Chu, P. C., 2015: Ekman spiral in horizontally inhomogeneous ocean with varying eddy viscosity. Pure Appl. 
Geophys., 172, 2831-2857, https://doi.org/10.1007/s00024015-1063-4.

— , and K. F. Cheng, 2008: South China Sea wave characteristics during Typhoon Muifa passage in winter 2004. J. Oceanogr., 64, 1-21, https://doi.org/10.1007/s10872-008-0001-9.

_ J. M. Veneziano, and C. Fan, 2000: Response of the South China Sea to Tropical Cyclone Ernie 1996. J. Geophys. Res., 105, 13 991-14 009, https://doi.org/10.1029/2000JC900035.

Craig, P. D., and M. L. Banner, 1994: Modeling wave-enhanced turbulence in the ocean surface layer. J. Phys. Oceanogr., 24, 2546-2559, https://doi.org/10.1175/1520-0485(1994)024<2546: MWETIT $>2.0 . \mathrm{CO} ; 2$.

Craik, A. D. D., and S. Leibovich, 1976: A rational model for Langmuir circulation. J. Fluid Mech., 73, 401-426, https:// doi.org/10.1017/S0022112076001420.

Dietrich, J. C., and Coauthors, 2011: Modeling hurricane waves and storm surge using integrally coupled scalable computations. Coastal Eng., 58, 45-65, https://doi.org/10.1016/ j.coastaleng.2010.08.001.

Drennan, W. M., M. A. Donelan, E. A. Terray, and K. B. Katsaros, 1996: Oceanic turbulence dissipation measurements in SWADE. J. Phys. Oceanogr., 26, 808-815, https://doi.org/ 10.1175/1520-0485(1996)026<0808:OTDMIS > 2.0.CO;2.

Emanuel, K. A., 1995: Sensitivity of tropical cyclones to surface exchange coefficients and revised steady-state model incorporating eye dynamics. J. Atmos. Sci., 52, 3969-3976, https:// doi.org/10.1175/1520-0469(1995)052<3969:SOTCTS >2.0.CO;2.

Ezer, T., and G. L. Mellor, 2004: A generalized coordinate ocean model and a comparison of the bottom boundary layer dynamics in terrain-following and in $z$-level grids. Ocean Modell., 6, 379-403, https://doi.org/10.1016/S1463-5003(03)00026-X.

Fan, Y., I. Ginis, T. Hara, C. W. Wright, and E. J. Walsh, 2009: Numerical simulations and observations of surface wave fields under an extreme tropical cyclone. J. Phys. Oceanogr., 39, 2097-2116, https://doi.org/10.1175/2009JPO4224.1.

Flather, R. A., 1976: A tidal model of the north-west European continental shelf. Mem. Soc. Roy. Sci. Liege, 6, 141-164.

Han, G. J., and Coauthors, 2011: A regional ocean reanalysis system for coastal waters of China and adjacent seas. Adv. Atmos. Sci., 28, 682-690, https://doi.org/10.1007/s00376-010-9184-2.

Harcourt, R. R., 2013: A second-moment closure model of Langmuir turbulence. J. Phys. Oceanogr., 43, 673-697, https:// doi.org/10.1175/JPO-D-12-0105.1.

—, 2015: An improved second-moment closure model of Langmuir turbulence. J. Phys. Oceanogr., 45, 84-103, https:// doi.org/10.1175/JPO-D-14-0046.1.

— muir turbulence in pure wind seas. J. Phys. Oceanogr., 38 1542-1562, https://doi.org/10.1175/2007JPO3842.1.

Holthuijsen, L. H., M. D. Powell, and J. D. Pietrzak, 2012: Wind and waves in extreme hurricanes. J. Geophys. Res., 117, C09003, https://doi.org/10.1029/2012JC007983.

Hsu, J.-Y., R.-C. Lien, E. A. D'Asaro, and T. B. Sanford, 2017: Estimates of surface wind stress and drag coefficients in Typhoon Megi. J. Phys. Oceanogr., 47, 545-563, https://doi.org/ 10.1175/JPO-D-16-0069.1.

Huang, C. J., and F. Qiao, 2010: Wave-turbulence interaction and its induced mixing in the upper ocean. J. Geophys. Res., 115 C04026, https://doi.org/10.1029/2009JC005853.

Huang, N. E., 1979: On surface drift currents in the ocean. J. Fluid Mech., 91, 191-208, https://doi.org/10.1017/S0022112079000112.

Jarosz, E., D. A. Mitchell, D. W. Wang, and W. J. Teague, 2007: Bottom-up determination of air-sea momentum exchange under a major tropical cyclone. Science, 315, 1707-1709, https://doi.org/10.1126/science.1136466.

Jones, N. L., and S. G. Monismith, 2008: Modeling the influence of wave-enhanced turbulence in a shallow tide- and wind-driven water column. J. Geophys. Res., 113, C03009, https://doi.org/ 10.1029/2007JB005482.

Kantha, L. H., 2003: On an improved model for the turbulent PBL. J. Atmos. Sci., 60, 2239-2246, https://doi.org/10.1175/ 1520-0469(2003)060<2239:OAIMFT >2.0.CO;2.

—, and C. A. Clayson, 2004: On the effect of surface gravity waves on mixing in the oceanic mixed layer. Ocean Modell., 6, 101-124, https://doi.org/10.1016/S1463-5003(02)00062-8. P. Wittmann, M. Sclavo, and C. A. Clayson, 2009: A preliminary estimate of the Stokes dissipation of wave energy in the global ocean. Geophys. Res. Lett., 36, L02605, https:// doi.org/10.1029/2008GL036193.

_ U. Lass, and H. Prandke, 2010: A note on Stokes production of turbulence kinetic energy in the oceanic mixed layer: Observations in the Baltic Sea. Ocean Dyn., 60, 171-180, https:// doi.org/10.1007/s10236-009-0257-7.

Kennedy, A. B., and Coauthors, 2011: Origin of the Hurricane Ike forerunner surge. Geophys. Res. Lett., 38, L08608, https:// doi.org/10.1029/2011GL047090.

Kitaigorodskii, S. A., M. A. Donelan, J. L. Lumley, and E. A. Terray, 1983: Wave turbulence interactions in the upper ocean. Part II: Statistical characteristics of wave and turbulent components of the random velocity field in the marine surface layer. J. Phys. Oceanogr., 13, 1988-1999, https://doi.org/ 10.1175/1520-0485(1983)013<1988:WTIITU>2.0.CO;2.

Kukulka, T., A. J. Plueddemann, and P. P. Sullivan, 2012: Nonlocal transport due to Langmuir circulation in a coastal ocean. J. Geophys. Res., 11, C12007, https://doi.org/10.1029/ 2012JC008340.

Large, W. G., J. C. McWilliams, and S. C. Doney, 1994: Oceanic vertical mixing: A review and a model with a nonlocal boundary layer parameterization. Rev. Geophys., 32, 363-403, https://doi.org/10.1029/94RG01872.

Li, M., and C. Garrett, 1993: Cell merging and the jet/downwelling ratio on Langmuir circulation. J. Mar. Res., 51, 737-769, https://doi.org/10.1357/0022240933223945.

$\longrightarrow,-$, and E. Skyllingstad, 2005: A regime diagram for classifying turbulent large eddies in the upper ocean. Deep-Sea Res. I, 52, 259-278, https://doi.org/10.1016/j.dsr.2004.09.004.

Li, S., M. Ming, P. G. Gregory, and J. B. Song, 2013: Roles of breaking waves and Langmuir circulation in the surface boundary layer of a coastal ocean. J. Geophys. Res. Oceans, 118, 5713-5187, https://doi.org/10.1002/jgrc.20387.

Li, W., Y. Xie, Z. He, G. Han, K. Liu, J. Ma, and D. Li, 2008: Application of the multigrid data assimilation scheme to the China Seas' temperature forecast. J. Atmos. Oceanic Technol., 25, 2106-2116, https://doi.org/10.1175/2008JTECHO510.1.

Li, Y., S. Peng, J. Wang, and J. Yan, 2014: Impacts of nonbreaking wave-stirring-induced mixing on the upper ocean thermal structure and typhoon intensity in the South China Sea. J. Geophys. Res. Oceans, 119, 5052-5070, https://doi.org/ 10.1002/2014JC009956.

McWilliams, J. C., and J. M. Restrepo, 1999: The wavedriven ocean circulation. J. Phys. Oceanogr., 29, 25232540, https://doi.org/10.1175/1520-0485(1999)029<2523: TWDOC $>2.0 . \mathrm{CO} ; 2$.

, and B. Fox-Kemper, 2013: Oceanic wave-balanced surface fronts and filaments. J. Fluid Mech., 730, 464-490, https:// doi.org/10.1017/jfm.2013.348. 
P. P. Sullivan, and C. H. Moeng, 1997: Langmuir turbulence in the ocean. J. Fluid Mech., 334, 1-30, https://doi.org/10.1017/ S0022112096004375.

— , E. Huckle, J. H. Liang, and P. P. Sullivan, 2012: The wavy Ekman layer: Langmuir circulations, breaking waves, and Reynolds stress. J. Phys. Oceanogr., 42, 1793-1816, https:// doi.org/10.1175/JPO-D-12-07.1.

,,--- , and -2014 : Langmuir turbulence in swell. J. Phys. Oceanogr., 44, 870-890, https://doi.org/10.1175/JPOD-13-0122.1.

Mellor, G. L., and T. Yamada, 1982: Development of a turbulence closure models for geophysical fluid problems. Rev. Geophys., 20, 851-875, https://doi.org/10.1029/RG020i004p00851.

— , and A. F. Blumberg, 2004: Wave breaking and ocean surface layer thermal response. J. Phys. Oceanogr., 34, 693-698, https://doi.org/10.1175/2517.1.

Pearson, B. C., A. L. M. Grant, J. A. Polton, and S. E. Belcher, 2015: Langmuir turbulence and surface heating in the ocean surface boundary layer. J. Phys. Oceanogr., 45, 2897-2911, https://doi.org/10.1175/JPO-D-15-0018.1.

Polton, J. A., and S. E. Belcher, 2007: Langmuir turbulence and deeply penetrating jets in an unstratified mixed layer. J. Geophys. Res., 112, C09020, https://doi.org/10.1029/ 2007JC004205.

Powell, M. D., P. J. Vickery, and T. A. Reinhold, 2003: Reduced drag coefficient for high wind speeds in tropical cyclones. Nature, 422, 279-283, https://doi.org/10.1038/nature01481.

Qiao, F., Y. Yuan, Y. Yang, Q. Zheng, C. Xia, and J. Ma, 2004: Wave-induced mixing in the upper ocean: Distribution and application to a global ocean circulation model. Geophys. Res. Lett., 31, L11303, https://doi.org/10.1029/2004GL019824.

Rabe, T. J., T. Kukulka, I. Ginis, T. Hara, B. G. Reichl, E. A. D'Asaro, R. R. Harcourt, and P. P. Sullivan, 2015: Langmuir turbulence under Hurricane Gustav (2008). J. Phys. Oceanogr., 45, 657-677, https://doi.org/10.1175/JPO-D-14-0030.1.

Reichl, B. G., D. Wang, T. Hara, I. Ginis, and T. Kukulka, 2016a: Langmuir turbulence parameterization in tropical cyclone conditions. J. Phys. Oceanogr., 46, 863-886, https://doi.org/ 10.1175/JPO-D-15-0106.1.

, T. Hara, I. Ginis, B. Thomas, T. Kukulka, and D. Wang, 2016b: Impact of sea-state-dependent Langmuir turbulence on the ocean response to a tropical cyclone. Mon. Wea. Rev., 144, 4569-4590, https://doi.org/10.1175/MWR-D-16-0074.1.

Reynolds, R. W., T. M. Smith, C. Liu, D. B. Chelton, K. S. Casey, and M. G. Schlax, 2007: Daily high-resolution blended analysis for sea surface temperature. J. Climate, 20, 5473-5469, https:// doi.org/10.1175/2007JCLI1824.1.

Sinha, N., A. E. Tejada-Martinez, C. Akan, and C. E. Grosch, 2015: Toward a K-profile parameterization of Langmuir turbulence in shallow coastal shelves. J. Phys. Oceanogr., 45, 2869-2895, https://doi.org/10.1175/JPO-D-14-0158.1.

Skyllingstad, E. D., and D. W. Denbo, 1995: An ocean large-eddy simulation of Langmuir circulations and convection in the surface mixed layer. J. Geophys. Res., 100, 8501-8522, https:// doi.org/10.1029/94JC03202.

Soloviev, A. V., R. Lukas, M. Donelan, B. K. Haus, and I. Ginis, 2014: The air-sea interface and surface stress under tropical cyclones. Sci. Rep., 4, 5306, https://doi.org/10.1038/srep05306.
Stoney, L., K. Walsh, A. V. Babanin, M. Ghantous, P. Govekar, and I. Young, 2017: Simulated ocean response to tropical cyclones: The effect of a novel parameterization of mixing from unbroken surface waves. J. Adv. Model. Earth Syst., 9, 759-780, https://doi.org/10.1002/2016MS000878.

Sullivan, P. P., L. Romero, J. C. McWilliams, and W. K. Melville, 2012: Transient evolution of Langmuir turbulence in ocean boundary layers driven by hurricane winds and waves. J. Phys. Oceanogr., 42, 1959-1980, https://doi.org/10.1175/ JPO-D-12-025.1.

Suzuki, N., and B. Fox-Kemper, 2016: Understanding Stokes forces in the wave-averaged equations. J. Geophys. Res. Oceans, 121, 3579-3596, https://doi.org/10.1002/2015JC011566.

Tamura, H., Y. Miyazawa, and L.-Y. Oey, 2012: The Stokes drift and wave induced-mass flux in the North Pacific. J. Geophys. Res., 117, C08021, https://doi.org/10.1029/2012JC008113.

Terray, E. A., M. A. Donelan, Y. Agarwal, W. M. Drennan, K. Kahma, A. J. Williams, P. Hwang, and S. A. Kitaigorodskii, 1996: Estimates of kinetic energy dissipation under breaking waves. J. Phys. Oceanogr., 26, 792-807, https://doi.org/10.1175/ 1520-0485(1996)026<0792:EOKEDU > 2.0.CO;2.

Thorpe, S. A., 1984: The effect of Langmuir circulation on the distribution of submerged bubbles caused by breaking wind waves. J. Fluid Mech., 142, 151-170, https://doi.org/10.1017/ S0022112084001038.

Van Roekel, L. P., B. Fox-Kemper, P. P. Sullivan, P. E. Hamlington, and S. R. Haney, 2012: The form and orientation of Langmuir cells for misaligned winds and waves. J. Geophys. Res., 117, C05001, https://doi.org/10.1029/2011JC007516.

Wu, J., 1982: Wind-stress coefficients over sea surface from breeze to hurricane. J. Geophys. Res., 87, 9704-9706, https://doi.org/ 10.1029/JC087iC12p09704.

Zhang, L., X. Zhang, P. C. Chu, C. Guan, H. Fu, G. Chao, G. Han, and W. Li, 2017: Impact of sea spray on the Yellow and East China Seas thermal structure during the passage of Typhoon Rammasun (2002). J. Geophys. Res. Oceans, 122, 7783-7802, https://doi.org/10.1002/2016JC012592.

Zhang, X. F., G. J. Han, D. X. Wang, W. Li, and Z. J. He, 2011: Effect of surface wave breaking on the surface boundary layer of temperature in the Yellow Sea in summer. Ocean Modell., 38, 267-279, https://doi.org/10.1016/j.ocemod.2011.04.006.

,,--- Z. A. Deng, and W. Li, 2012: Summer surface layer thermal response to surface gravity waves in the Yellow Sea. Ocean Dyn., 62, 983-1000, https://doi.org/10.1007/s10236012-0547-3.

,,-- X. D. Wang, and L. X. Zhang, 2014: Effects of Stokes production on summer ocean shelf dynamics. Acta Oceanol. Sin., 33, 24-34, https://doi.org/10.1007/s13131-014-0424-7.

, D. Di, X. R. Wu, W. Li, and P. C. Chu, 2015: Variational estimation of wave-affected parameters in a two-equation turbulence model. J. Atmos. Oceanic Technol., 32, 528-546, https://doi.org/10.1175/JTECH-D-14-00087.1.

Zhang, X. S., Z. F. Wang, B. Wang, K. J. Wu, G. J. Han, and W. Li, 2014: A numerical estimation of the impact of Stokes drift on upper ocean temperature. Acta Oceanol. Sin., 33, 48-55, https://doi.org/10.1007/s13131-014-0507-5.

Zijlema, M., G. P. V. Vledder, and L. H. Holthuijsen, 2012: Bottom friction and wind drag for wave models. Coastal Eng., $\mathbf{6 5}$, 19-26, https://doi.org/10.1016/j.coastaleng.2012.03.002. 